\title{
Effects of prednisolone on the dystrophin-associated proteins in the blood-brain barrier and skeletal muscle of dystrophic mdx mice
}

\author{
Roberto Tamma ${ }^{1,6}$, Tiziana Annese ${ }^{1,6}$, Roberta F Capogrosso², Anna Cozzoli², Vincenzo Benagiano ${ }^{1}$, \\ Valeriana Sblendorio ${ }^{2}$, Simona Ruggieri ${ }^{1,3}$, Enrico Crivellato ${ }^{4}$, Giorgina Specchia ${ }^{5}$, Domenico Ribatti ${ }^{1}$, \\ Annamaria De Luca ${ }^{2,7}$ and Beatrice Nico ${ }^{1,7}$
}

The mdx mouse, the most widely used animal model of Duchenne muscular dystrophy (DMD), develops a seriously impaired blood-brain barrier (BBB). As glucocorticoids are used clinically to delay the progression of DMD, we evaluated the effects of chronic treatment with $\alpha$-methyl-prednisolone (PDN) on the expression of structural proteins and markers in the brain and skeletal muscle of the mdx mouse. We analyzed the immunocytochemical and biochemical expression of four BBB markers, including endothelial ZO-1 and occludin, desmin in pericytes, and glial fibrillary acidic protein (GFAP) in glial cells, and the expression of the short dystrophin isoform Dp 71, the dystrophin-associated proteins (DAPs), and aquaporin-4 (AQP4) and $\alpha-\beta$ dystroglycan (DG) in the brain. We evaluated the BBB integrity of $\mathrm{mdx}$ and PDN-treated mdx mice by means of intravascular injection of horseradish peroxidase (HRP). The expression of DAPs was also assessed in gastrocnemius muscles and correlated with utrophin expression, and laminin content was measured in the muscle and brain. PDN treatment induced a significant increase in the MRNA and protein content of the BBB markers; a reduction in the phosphorylation of occludin in the brain and of AQP4/ $\beta$ DG in both tissues; an increase of Dp71 protein content; and an increase of both mRNA and protein levels of the AQP4/ $\alpha-\beta$ DG complex. The latter was associated with enhanced laminin and utrophin in the muscle. The HRP assay demonstrated functional restoration of the BBB in the PDN-treated mdx mice. Specifically, mdx mice showed extensive perivascular labeling due to escape of the marker, while HRP was exclusively intravascular in the PDN-treated mice and the controls. These data illustrate for the first time that PDN reverses the BBB alterations in the $\mathrm{mdx}$ mouse and re-establishes the proper expression and phosphorylation of $\beta$-DG in both the BBB and skeletal muscle. Further, PDN partially protects against muscle damage. The reduction in AQP4 and occludin phosphorylation, coupled with their anchoring to glial and endothelial membranes in PDN-treated mice, suggests that the drug may target the glial and endothelial cells. Our results suggest a novel mechanism for PDN action on cerebral and muscular function, restoring the link between DAPs and the extracellular matrix, most likely through protein kinase inactivation.

Laboratory Investigation (2013) 93, 592-610; doi:10.1038/labinvest.2013.46; published online 25 March 2013

KEYWORDS: aquaporin-4; blood-brain barrier; dystrophin-associated proteins; dystrophic mice; glucocorticoids; muscular tissue

\footnotetext{
'Department of Basic Medical Sciences, Neurosciences and Sensory Organs, Section of Human Anatomy and Histology, University of Bari Medical School, Bari, Italy; ${ }^{2}$ Department of Bioscience, Biotechnology and Pharmacological Sciences, Section of Pharmacology, University of Bari Medical School, Bari, Italy; ${ }^{3}$ Department of Internal Medicine and Clinical Oncology, University of Bari Medical School, Bari, Italy; ${ }^{4}$ Department of Medical and Morphological Research, Anatomy Section, University of Udine Medical School, Bari, Italy and ${ }^{5}$ Department of Emergency and Organ Transplantation, Hematology Section, University of Bari Medical School, Bari, Italy Correspondence: Professor A De Luca, PhD, Department of Bioscience, Biotechnology and Pharmacological Sciences, Section of Pharmacology, University of Bari, Via Orabona 4, Bari 70125, Italy.

E-mail: annamaria.deluca@uniba.it

or Professor B Nico, PhD, Department of Basic Medical Sciences, Neurosciences and Sensory Organs, Section of Human Anatomy and Histology, University of Bari Medical School, Piazza Giulio Cesare, Bari, 11 Policlinico, Bari I-70124, Italy.

E-mail: beatrice.nico@uniba.it

${ }^{6}$ These authors contributed equally to this work.

${ }^{7}$ These authors contributed equally to the work as senior authors.

Received 2 November 2012; revised 29 January 2013; accepted 31 January 2013
} 
$\mathrm{X}$-linked chromosome mutations that result in the absence of the dystrophin protein cause Duchenne muscular dystrophy (DMD) in humans and a dystrophic phenotype in animals, including the $\mathrm{mdx}$ mouse. ${ }^{1,2} \mathrm{DMD}$ is characterized by progressive muscle weakness and wasting, and neural dysfunctions involving mental retardation and metabolic alterations have also been described. ${ }^{3}$

The molecular mechanisms underlying dystrophic brain dysfunction in DMD have not been completely clarified. Dystrophin is an actin-binding protein, which links cortical actin of the myofibers to the sarcolemma by dystrophin-associated proteins (DAPs). ${ }^{4-7}$ Dystrophin has several truncated isoforms, including Dp260, Dp140, Dp116, and Dp71, as well as a full-length conformations $(427 \mathrm{kDa})$, which have been demonstrated in the brain $^{8,9}$ and in the astrocyte perivascular endfeet, ${ }^{10}$ forming the glio-vascular units in the blood-brain barrier (BBB).

All of the dystrophin isoforms are less abundant in the central nervous system of both DMD patients ${ }^{11}$ and the $\mathrm{mdx}$ mouse. ${ }^{12}$ We previously demonstrated the dysfunction of the vascular compartment of the brain of the mdx mouse, which consists of brain edema, alterations of the BBB, decreased levels of the tight junction (TJ) -associated protein zonula occludens-1 (ZO-1), and decreased levels of the glial protein aquaporin-4 (AQP4). ${ }^{13,14}$

AQP4 has an important role in BBB function, modifying its expression and polarization when the BBB is damaged, inducing a consequent increase in vascular permeability and edema. ${ }^{15-17}$ AQP4 is also a component of the DAPs complex; it is present in the glial endfeet along with short dystrophin Dp71, ${ }^{18-21}$ where it colocalizes with $\alpha$ - $\beta$-dystroglycan (DG) proteins, ${ }^{22}$ which, in turn, are receptors for the basement membrane proteins laminin and agrin. ${ }^{23-25}$

Moreover, a number of studies suggest that the degree of phosphorylation of DAPs components is very important in normal cellular function. Activation of protein kinase C (PKC) leads to AQP4 phosphorylation-regulated water permeability and cell invasion in glioma cells. ${ }^{26}$ Also, $\beta$-DG undergoes phosphorylation in an adhesion-dependent manner in the skeletal muscle fibers; this is associated with enhanced-protein turnover by intracellular recycling. ${ }^{27}$ DAPs and dystrophin proteins are absent or reduced in both the skeletal muscle and the brains of patients affected by DMD and in mdx mice. ${ }^{13}$

We previously reported a deficiency in the dystrophin isoform (Dp71) in parallel with a reduction of DAPs components, such as $\alpha-\beta$ DG, $\alpha$-syntrophin, AQP4, and Kir 4.1 in the mdx perivascular glial endfeet. ${ }^{28}$ Moreover, we demonstrated that the mdx DAP deficiency correlated with loss in the anchoring of $\alpha-\beta$ DG to glial endfeet and with molecular alterations in the basement membrane. These results suggest that Dp71 and DAPs could be involved in the morphological and functional polarization of astrocytes in the BBB and that in the mdx brain, their deficiency, coupled with structural and molecular modifications of the basement membrane, could be responsible for the $\mathrm{BBB}$ alterations occurring in this pathological condition.

Glucocorticoids are the sole drugs used clinically to delay progression in DMD, improving strength and functional outcome ${ }^{29}$ but they have considerable side effects with chronic use. ${ }^{30,31}$ Their mechanism of action in dystrophic muscle is far from clear, but comprises a generalized stabilizing effect on myofibers and a reduction of necrosis, likely via their antiinflammatory action. ${ }^{32-34}$ However, multiple additional mechanisms have been proposed. Accordingly, we have demonstrated in $\mathrm{mdx}$ mice that $\alpha$-methyl-prednisolone (PDN) treatment lessens exercise-induced weakness in vivo and ameliorates the excitation-contraction coupling of isolated muscle. In parallel, PDN improves the histopathological profiles, reducing the markers of oxidative stress and upregulating utrophin, a surrogate of dystrophin. ${ }^{35,36}$ This latter effect of PDN likely occurs at translational level. ${ }^{37}$ Therefore, the preclinical use of glucocorticoids can be used to determine their mechanisms of action, and can help in the development of strategies to potentiate therapeutic approaches to DMD. Because of the multiplicity of tissues targeted by glucocorticoids, other effects of the drugs cannot be ruled out; however, no data are available concerning the effects of corticosteroids on $\mathrm{mdx}$ mouse brain. In the clinical setting, glucocorticoids are used to reduce BBB permeability in many pathological conditions, highlighting the importance of a more detailed preclinical analysis of PDN action in dystrophic subjects. ${ }^{38}$

In this study, we evaluated the effects of chronic treatment with PDN in both the brain and muscle of mdx mice, by analyzing the immunocytochemical and biochemical expression of four $\mathrm{BBB}$ markers, including $\mathrm{ZO}-1$ and occludin in the endothelium, desmin in pericytes, and glial fibrillary acidic protein (GFAP) in glial cells, and the expression of the short dystrophin isoform Dp 71 and of the DAPs, AQP4, and $\alpha-\beta$ DG in the brain. We also evaluated the BBB integrity of the $\mathrm{mdx}$ and PDN-treated $\mathrm{mdx}$ mice by means of intravascular injection of horseradish peroxidase (HRP). The expression of the DAPs complex was also assessed in gastrocnemius muscles (GC) and correlated with utrophin and laminin content. The results provide the first evidence that PDN ameliorates brain vessels as well as muscles function of dystrophic mice by restoring the proper interactions between DAPs and the extracellular matrix, likely by protein kinase inactivation.

\section{MATERIALS AND METHODS \\ Animals}

A total of 30 male mice, $15 m d x$ (C57BL/10ScSn mdx, Jackson Laboratory, Bar Harbor, ME, USA) and 15 control mice $(\mathrm{C} 57 \mathrm{BL} / 10 \mathrm{ScSn})$ were used. Treatment with PDN started at $4-5$ weeks of age; PDN was given by intraperitoneal injection at $1 \mathrm{mg} / \mathrm{kg}, 6$ days a week, at a maximal injected volume of $0.1 \mathrm{ml} / 10 \mathrm{~g}$ of body weight. Drug administration was performed in parallel with a standard protocol of exercise 
on a treadmill according to the standard operating procedure described elsewhere. ${ }^{39,40}$ The maintenance of a constant protocol of exercise and treatment was chosen in order to allow unbiased comparison of drug effects with those obtained in previous trials. ${ }^{35}$ Control wild-type animals, age and gender-matched, underwent similar protocols and daily injection of vehicle (sterile water) as needed. Because of the well-described effect of exercise in the mdx phenotype, ${ }^{36,39}$ the use of a group of sedentary $\mathrm{mdx}$ mice or wild-type exercised mice was not considered informative for the purpose of the present study and was regarded as unethical.

Every week the animals were monitored for body weight and forelimb force, as described in detail elsewhere. ${ }^{35}$ The values at the fourth week were used for statistical analysis. The treatment lasted 4-8 weeks, and the age of the animals at the time of killing was $2-3$ months.

Animals were killed by cervical dislocation or urethane overdose, based on the experimental need. Whole-brain, including cerebellum and GC, were removed, divided into two parts, and used in parallel for morphological and biochemical analysis. Extensor digitorum longus (EDL) muscles were removed and placed in muscle chambers for electrophysiological or contraction measurements. ${ }^{41}$ Blood was obtained from the heart and plasma prepared for spectrophotometric determination of creatine kinase (CK) activity using a commercial kit (Sentinel, Farmalab, Italy). ${ }^{36}$ This study was carried out in strict accordance with the recommendations in the Guide for the Care and Use of Laboratory Animals of the National Institutes of Health. The protocol was approved by the Local Committee on the Ethics of Animal Experiments of the University of Bari. All surgery was performed under sodium pentobarbital anesthesia, and all efforts were made to minimize suffering.

\section{Antibodies}

The following antibodies were used to detect specific water channel, DAPs, TJ, glial, and pericyte proteins: polyclonal rabbit anti-AQP4 antiserum (Santa Cruz Biotechnology, Santa Cruz, CA, USA), monoclonal mouse anti- $\alpha$-DG (Chemicon International Inc., Temecula, CA, USA), monoclonal mouse anti- $\beta$ DG (Novocastra, Newcastle, UK), monoclonal mouse anti-Dp71 (Mandra 1, Sigma-Aldrich, USA; Mandra 1 antibody strongly stains the full-length dystrophin in the muscle, whereas in the brain it recognizes only the $71-\mathrm{kDa}$ protein as demonstrated in our previous study ${ }^{20,28}$ ), monoclonal mouse anti-desmin (Dako, Glostrup, Denmark), polyclonal rabbit anti-ZO-1 (Abcam, Cambridge, UK), polyclonal rabbit anti-occludin (Santa Cruz Biotechnology), polyclonal rabbit anti-GFAP (Immunostar Inc, Hudson, WI, USA), polyclonal rabbit anti-FVIII (Dako), monoclonal mouse anti-myosin (Sigma-Aldrich, St Louis, MO, USA), polyclonal goat anti-utrophin (Santa Cruz Biotechnology), and polyclonal rabbit anti-laminin (EuroDiagnostica, Malmö, Sweden). The antisera were used at a dilution of 1:100 with the exception of anti-Dp71 Mandra
(1:20), anti-occludin (1: 10), anti-GFAP (1: 1) and antiutrophin (1:35). The secondary goat anti-mouse and antirabbit antibodies labeled with Alexa Fluor 488 and Alexa Fluor 555 dyes (Invitrogen, Carlsbad, CA, USA) diluted 1:300 were used. As controls, the primary antibody was omitted.

\section{Fixation and Preparation of Tissue}

Small pieces of parietal brain cortex and GC muscles were fixed in $4 \%$ paraformaldehyde in $0.1 \mathrm{M}$ phosphate buffer for immunohistochemical investigation, immunofluorescence, and confocal laser microscopy. In addition, some small pieces of brain cortex were coated with OCT mounting media and frozen in isopentane cooled by liquid nitrogen for immunofluorescence and confocal laser microscopy.

\section{Dual Immunofluorescence-Confocal Laser Scanning Microscopy}

Deparaffinized brain sections and cryosectioned samples $12 \mu \mathrm{m}$ thick obtained from three $\mathrm{mdx}$ and three control brains were utilized. The sections were incubated for $30 \mathrm{~min}$ in a blocking buffer (phosphate-buffered saline (PBS), $\mathrm{pH}$ $7.4,1 \%$ bovine serum albumin, and $2 \%$ fetal calf serum), and for antigen retrieval they were heated in a steamer citrate buffer, pH 6.0 for $4 \mathrm{~min}$ and coated in PBS buffer. The sections were then exposed to primary antibodies diluted in the same solution overnight at $4{ }^{\circ} \mathrm{C}$. After washing in PBS the sections were incubated for $2 \mathrm{~h}$ with the secondary antibodies at room temperature and following washing they were incubated for $5 \mathrm{~min}$ with $0.01 \%$ TO-PRO-3 (Invitrogen) for nuclear staining, and mounted in Vectashield (Vector Laboratories, Burlingame, CA, USA). The sections were examined under a Leica TCS SP2 (Leica, Wetzlar, Germany) confocal laser scanning microscope using $\times 40$ and $\times 63$ objective lenses with either $1 \times$ or $2 \times$ zoom factors. A sequential scan procedure was applied during image acquisition of the two fluorophores. Confocal images were taken at 200-nm intervals through the $z$ axis of the section covering a total depth of $10 \mu \mathrm{m}$. Images from individual optical planes and multiple serial optical sections were analyzed, digitally recorded, and stored as TIFF files using Adobe Photoshop software (Adobe Systems Inc. San Jose, CA, USA).

\section{ZO-1 Immunocytochemistry}

Five-micrometer-thick histological sections collected on poly- $L$-lysine-coated slides (Sigma Chemical) were deparaffinized and stained with a three-layer avidin-biotin-immunoperoxidase system technique. The sections were rehydrated in a xylene-graded alcohol scale and then rinsed for $10 \mathrm{~min}$ in $0.1 \mathrm{M}$ PBS. The sections were treated with $2.5 \%$ ficin (Sigma Chemical) in PBS for $5 \mathrm{~min}$ at $37^{\circ} \mathrm{C}$, and then exposed to polyclonal rabbit anti-ZO-1 diluted 1:30 in PBS overnight at $4{ }^{\circ} \mathrm{C}$. After $3 \times 5$ min washings in PBS, the sections were incubated with biotinylated swine anti-rabbit Ig (Multi-Link, Dako Corporation, Milan, Italy) diluted 1:150 in PBS $1 \mathrm{~h}$ at room temperature, and streptavidin-peroxidase 
conjugate (Dako Corporation) diluted 1:150 in PBS for 30 min at room temperature. Immunodetection was performed in distillated water with AEC substrate kit for peroxidase (Vector Laboratories) for $40 \mathrm{~min}$ at room temperature. Afterward, the sections were washed in the distillated water and counterstained with Gill's hematoxylin number 2 (Polysciences, Warrington, PA, USA), and mounted in buffered glycerin. Specific preimmune serum (Dako Corporation) replacing the primaries antibodies served as a negative control.

\section{Morphometric Analysis of Occludin, Desmin, Laminin, GFAP, AQP4, $\alpha / \beta$ DG, and Dp71 Expression}

Morphometric analysis was performed on 10 fields for section over three sections for brain from at least three animals per experimental group, observed at $\times 400$ magnification by using an Image Analysis software (Olympus Italia, Rozzano, Italy). A total number of 80 vessels for each animal group was analyzed. Occludin, Desmin, Laminin, GFAP, AQP4, $\alpha / \beta$ DG, and Dp71-labeled areas were evaluated. The mean value in each image from the section, the final mean value for all the images and s.e.m. were calculated. The statistical significance of the differences between the mean values of the labeled area between wild-type, $\mathrm{mdx}$, and PDN mdx-treated mice were determined by Student's $t$-test with GraphPad Prism 3.0 software (GraphPad software, La Jolla, CA, USA). The findings were considered significant at $P$-values $<0.05$.

\section{HRP Assay}

In a parallel experimental series, control, $\mathrm{mdx}$, and PDNtreated $\mathrm{mdx}$ mice received an intracardial injection of HRP (0.3 mg Sigma type II HRP per gram body weight in $0.1 \mathrm{ml}$ saline solution). After $5 \mathrm{~min}$ the mice were decapitated and the brains were fixed by immersion in $3 \%$ glutaraldehyde in $0.1 \mathrm{M}$ sodium cacodylate buffer $(\mathrm{pH}=7.3)$ for $3 \mathrm{~h}$ at $4{ }^{\circ} \mathrm{C}$, and then washed in the same buffer for $12 \mathrm{~h}$. Sections of $50 \mu \mathrm{m}$ were cut with a Vibratome and incubated for $30 \mathrm{~min}$ at room temperature in a $0.05 \%$ solution of $3.3^{\prime}$-diaminobenzidine in $0.05 \mathrm{M}$ Tris- $\mathrm{HCl}$ buffer $(\mathrm{pH}=7.6)$ containing $0.01 \% \mathrm{H}_{2} \mathrm{O}_{2}$. After incubation, some of the slices were dehydrated, mounted on slides and examined under SM Leitz Dialux 20 photomicroscope (Leitz, Wetzlar, Germany).

\section{Real-Time PCR}

cDNA was amplified with SsoFast Evagreen Supermix (Bio-Rad Laboratories, Hercules, CA, USA) and PCR amplification was performed using the CFX96 Real-Time PCR Detection System (Bio-Rad Laboratories). The expression of mRNA for occludin, $\alpha / \beta$-DG, desmin, ZO-1, AQP4, GFAP, laminin and actin as housekeeping genes was evaluated by real-time PCR, and the samples were normalized to $\beta$-actin. The primer sequences (Operon Biotechnologies $\mathrm{GmbH}$, Cologne, Germany) are reported in Table 1. All experiments were performed with $60{ }^{\circ} \mathrm{C}$ as the annealing temperature. The amplification process included 40 cycles, each consisting of three steps: incubation at $95{ }^{\circ} \mathrm{C}$ for $30 \mathrm{~s}$; incubation at
Table 1 Primer sequences for real-time PCR

$\begin{array}{ll}\text { ZO-1/S } & 5^{\prime} \text {-CAATCACCATCTCTTCACAACTAC-3' } \\ \text { ZO-1/AS } & 5^{\prime} \text {-TAGCACCATCCGCCTTCC-3' } \\ \text { DG } \alpha / S & 5^{\prime} \text {-GCCTTCTCCAATGCTCTG-3' } \\ \text { DG } \alpha / A & 5^{\prime} \text {-TCCTCACTGCTCTTCTCG-3' } \\ \text { OCCLUDIN/S } & 5^{\prime} \text {-GAGGCTATGGCTATGGCTATGG-3' } \\ \text { OCCLUDIN/AS } & 5^{\prime} \text {-AGGAAGCGATGAAGCAGAAGG-3' } \\ \text { AQP4/S } & 5^{\prime} \text {-GAGTATGTCTTCTGTCCTG-3' } \\ \text { AQP4/AS } & 5^{\prime} \text {-ACGGTCAATGTCAATCAC-3' } \\ \text { DESMIN/S } & 5^{\prime} \text {-ACCTTCTCTGCTCTCAACTTCC-3' } \\ \text { DESMIN/AS } & 5^{\prime} \text {-CGCTGACAACCTCTCCATCC-3' } \\ \text { ACTIN/S } & 5^{\prime} \text {-ACCACACCTTCTACAATGAG-3' } \\ \text { ACTIN/AS } & 5^{\prime} \text {-ACGACCAGAGGCATACAG-3' } \\ \text { DG } \beta / S & 5^{\prime} \text {-AGGACACCACCACTGACAAG-3' } \\ \text { DG } \beta / A & 5^{\prime} \text {-GCATCCACAGCCGACAGG-3' } \\ \text { GFAP/S } & 5^{\prime} \text {-AGAGACAGAGGAGTGGTATCG-3' } \\ \text { GFAP/AS } & 5^{\prime} \text {-GCTTCGTGCTTGGCTTGG-3' } \\ \text { LAM/S } & 5^{\prime} \text {-AAGAAGGCGACTGTAAGG-3' }\end{array}$

$95^{\circ} \mathrm{C}$ for $5 \mathrm{~s}$; and annealing and extension at $60^{\circ} \mathrm{C}$ for $5 \mathrm{~s}$. Therafter, the last cycle, the melting curves analysis, was performed at $65-95{ }^{\circ} \mathrm{C}$ interval by increasing the temperature by $0.5{ }^{\circ} \mathrm{C}$. The fold change values were calculated according to the method of Pfaffl. ${ }^{42}$ The plotted results were derived from three independent experiments performed in triplicate.

\section{Western Blot}

Brains of $10 \mathrm{mdx}, 10 \mathrm{PDN}$-treated $\mathrm{mdx}$, and 10 control mice were homogenized with a Polytron apparatus in a lysis buffer containing $20 \mathrm{mM}$ Tris- $\mathrm{HCl} \mathrm{pH} 7.5,1 \%(\mathrm{v} / \mathrm{v})$ Triton X-100, $1 \%(\mathrm{v} / \mathrm{v}) \mathrm{NP}-40,2 \mathrm{mM} \mathrm{MgCl} 2,5 \mathrm{mM}$ EDTA, $150 \mathrm{mM} \mathrm{NaCl}$, $0.2 \mathrm{mM}$ phenylmethylsulfonyl fluoride, $1 \mathrm{mM} \mathrm{NaVO}_{4}, 10 \mathrm{mM}$ $\mathrm{NaF}$ and protease inhibitors. After centrifugation at $1000 \times \mathrm{g}$ for $10 \mathrm{~min}$, the protein concentration of the supernatant was determined using the detergent-compatible Bio-Rad DC protein assay (Bio-Rad Laboratories). For immunoblotting, $30 \mu \mathrm{g}$ per lane of protein extract was solubilized in Laemmli buffer, boiled at $90^{\circ} \mathrm{C}$ for $5 \mathrm{~min}$ and resolved on a $7.5-12 \%$ polyacrylamide gel; thereafter, the proteins were electrotransferred to a nitrocellulose membrane (Amersham Bioscience, Buckinghamshire, UK). Blots were blocked with PBS blocking buffer containing 5\% nonfat dry milk for $1 \mathrm{~h}$ and incubated overnight at $4{ }^{\circ} \mathrm{C}$ with the following primary antibodies: rabbit anti-AQP4 (Santa Cruz Biotechnology), rabbit anti-occludin (Santa Cruz Biotechnology), rabbit antiZO-1 (Abcam), mouse anti- $\alpha$-DG (Santa Cruz Biotechnology), mouse anti- $\beta$-DG (Novocastra), mouse anti-phospho- $\beta$-DG (Abcam), polyclonal rabbit anti-laminin (Euro-Diagnostica), 

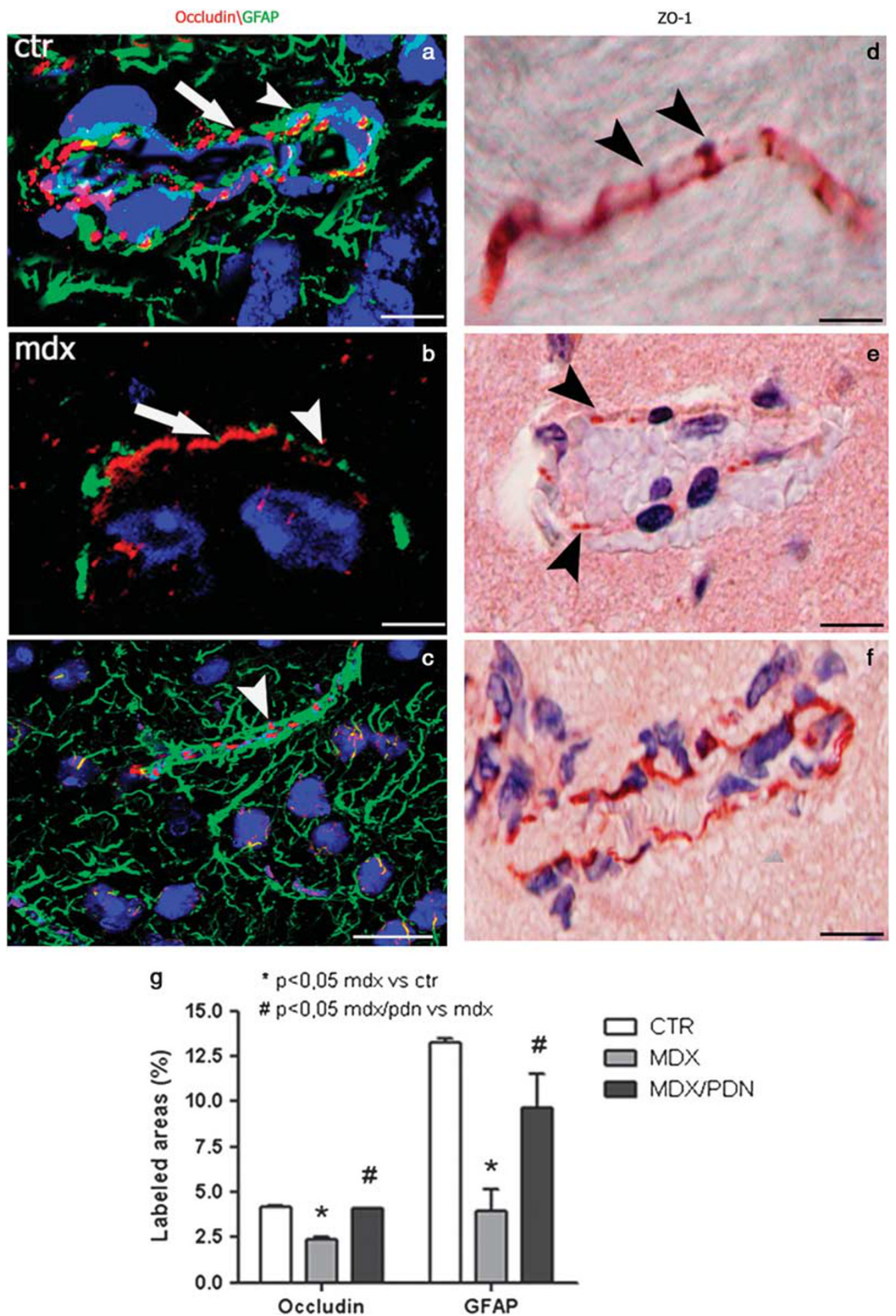

Figure 1 Confocal dual immunofluorescence reaction of occludin (red) and GFAP (green) (a-c), ZO-1 immunocytochemistry (d-f), and morphometric analysis of occludin and GFAP expression (g). (a) Control vessel showing a pointed occludin expression along the entire luminal side (arrow), enveloped by glial processes intensely GFAP marked (arrowhead). (b) Mdx vessel showing a linear fluorescence expression of occludin (arrow) for part of the tract of the luminal surface and a poorly enveloping of GFAP glial processes (arrowhead). (c) PDN mdx vessel showing a restoration of punctuate occludin expression on the luminal side and GFAP glial labeling on the abluminal side (arrowhead). (d-f) The mdx brain showed reduced ZO-1 labeling along the luminal vascular side (e, arrowhead) compared with control (d, arrowhead), and increased ZO-1 expression after PDN treatment (f). Scale bar: a, $\mathbf{b}$, e, f, $16,6 \mu \mathrm{m} ; \mathbf{c}, 25 \mu \mathrm{m} ; \mathbf{d}, 10 \mu \mathrm{m}$. (g) Occludin and GFAP expression is lower in mdx mice, while a significant increase in PDN-treated mice compared with the $\mathrm{mdx}$ animals is detected (Figure 1g). 
mouse anti-Dp71 (Clone Mandra 1-Sigma-Aldrich), mouse anti-desmin (Dako), goat anti-GFAP (Santa Cruz Biotechnology), and mouse anti- $\beta$-actin (Santa Cruz Biotechnology). After the primary antibody treatment, the membranes were washed $4 \times$ for $5 \mathrm{~min}$ each at room temperature in PBS $+0.1 \%$ Tween-20 before the addition of secondary antibodies. PBS and $0.1 \%$ Tween-20-diluted secondary antibodies (anti-mouse, rabbit, and goat) were IRDye labeled (680/ 800CW) (LI-COR Biosciences, Lincoln, NE, USA). For immunoblot analysis, the Li-cor Odyssey infrared imaging system was used (LI-COR). The western blot images were analyzed by imaging densitometry using Quantity One Software (Bio-Rad Laboratories), and expressed as optical density $\times \mathrm{mm}^{2}$. All the numeric data are conventionally expressed as percentage of protein expression respect to the actin (actin expression is considered as $100 \%)$. The images are representative of three independent experiments performed in triplicate.

\section{Immunoprecipitation}

For phospho-AQP4 (P-AQP4), phospho-occludin (P-occludin) and their unphosphorylated forms immunoprecipitation, $150 \mu \mathrm{g}$ of protein extract from brains and muscles, $10 \mathrm{mdx}$, 10 PDN-treated mdx, and 10 control mice were solubilized in lysis buffer and incubated for $1 \mathrm{~h}$ in ice and shaking with $10 \mu \mathrm{g}$ of polyclonal anti-P-ser antibody (Millipore). Then $20 \mu \mathrm{l}$ of protein G-Sepharose (Amersham Bioscience) was added, and samples were incubated overnight at $4{ }^{\circ} \mathrm{C}$ on a roller for mixing, and the next day pelleted and twice washed with lysis buffer. Samples were centrifuged for $2 \mathrm{~min}$ at 13000 r.p.m. and resuspended in Laemmli sample buffer, boiled for 5 min and separated on 10\% SDS-polyacrylamide gels. They were then transferred to a nitrocellulose membrane, and immunoblotting was performed by blocking the membrane with 5\% nonfat dry milk in TBST. P-AQP4/AQP4 and P-occludin/occludin were detected by blotting with anti-AQP4 antibody (Santa Cruz Biotechnology) diluted 1:500 and anti-occludin (Santa Cruz Biotechnology) diluted 1:500, respectively, followed by PBS and 0.1\% Tween-20diluted secondary antibodies (rabbit) IRDye labeled (680/ 800CW) (LI-COR Biosciences). For immunoblot analysis, the Li-cor Odyssey infrared imaging system was used (LI-COR).

\section{Statistics}

Results are given as mean \pm s.e.m. Statistical analyses were performed by using Student's $t$-tests for significant differences at $P<0.05$.

\section{Functional Recordings}

EDL muscles were removed intact tendon-to-tendon and placed in muscle baths containing oxygenated physiological solutions of standard composition. ${ }^{36}$ The mechanical threshold was determined using a two microelectrode 'point' voltage clamp method. ${ }^{36,41}$ In brief, the two microelectrodes (spaced about $50 \mu \mathrm{m}$ ) were inserted into the central region of
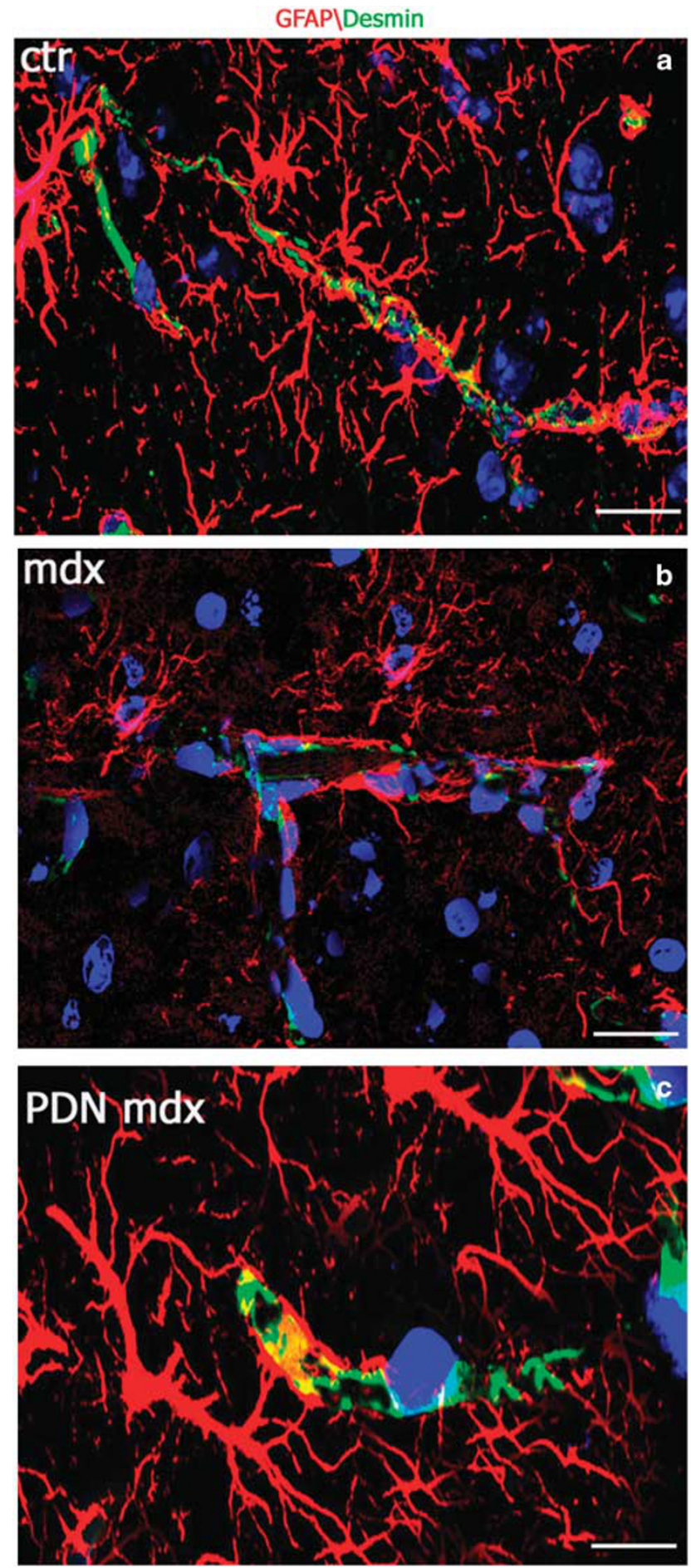

Figure 2 Confocal dual immunofluorescence reaction of GFAP (red) and Desmin (green) in control (a), $\mathrm{mdx}$ (b) and PDN mdx vessels. (c) The $\mathrm{mdx}$ vessel is poorly subtended by a light green fluorescent signal of desmin and enveloped by a few labeled glial endfeet (b). The control (a) and PDN mdx vessels (c) show intense and pointed desmin green signal and strongly labeled glial processes encircling their wall. Scale bar: $\mathbf{a}, \mathbf{b}$, $400 \mu \mathrm{m} ; \mathrm{c}, 16,6 \mu \mathrm{m}$.

a superficial fiber and continuously viewed using a stereomicroscope ( $\times 100$ magnification). Depolarizing command pulses of duration ranging from 500 to $5 \mathrm{~ms}(0.3 \mathrm{~Hz})$ were 


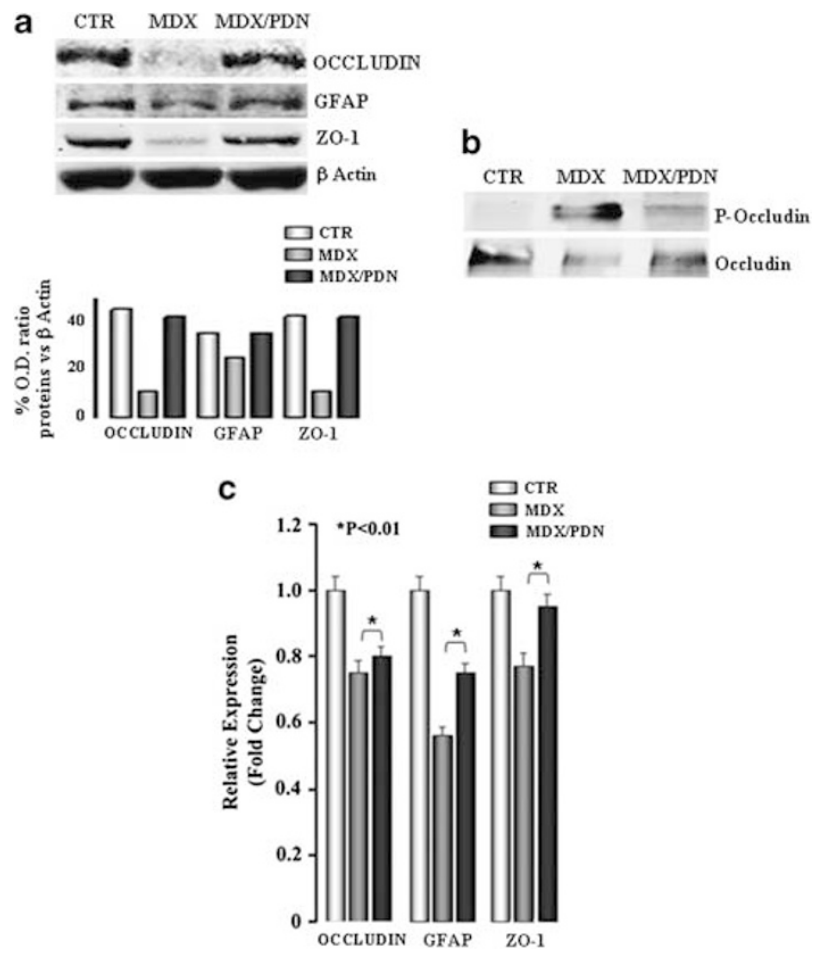

Figure 3 (a) Western blotting analysis of occludin, ZO-1, and GFAP, in the brain homogenates from, respectively, 10 control, $\mathrm{mdx}$, and PDN $m d x$-treated mice. Mdx mice show lower expression of these proteins than the controls. The treatment with PDN restores the protein levels to that of the control animals. Quantification of the bands reveals a higher level of all proteins in PDN-treated mdx mouse brain compared with the $\mathrm{mdx}$ animals. The data are representative of three independent experiments from each group. (b) The immunoprecipitation of occludin and its phosphorylated form shows less phosphorylated occludin in $\mathrm{mdx}$ mice compared with the controls, and a reduction of phoshorylation in the mdx mice after PDN treatment. The occludin immunoprecipitate control experiment shows the same result as the western blot in panel a. (c) Real-time PCR evaluation shows a significant downregulation of occludin, ZO-1, and GFAP mRNA level in the mdx brain. Data are representative of three independent experiments from 10 animals for each group. Statistics: Student's $t$-test comparing $\mathrm{mdx}$ mice with wildtype animals as result of the three independent experiments performed in triplicate; ${ }^{*} P<0.01$.

given from the holding potential $(\mathrm{H})$ of $90 \mathrm{mV}$ until visible contraction. The threshold membrane potential $(\mathrm{V}$, in $\mathrm{mV})$ was read on a digital sample-and-hold millivoltmeter for each fiber at the various pulse durations $t$ (in ms); mean values at each $t$ allowed the construction of a 'strengthduration' curve; fit of data points to a classical nonlinear least square algorithm allowed to calculate the rheobase voltage $(R$, in $\mathrm{mV}) .{ }^{41}$ For contractile recordings, one tendon side of EDL was fixed to a force transducer (1N 300C-LR, Aurora Scientific Inc., Canada) and connected to interface and acquisition units (Dynamic Muscle Control Acquisition System vs 4.1.6, ASI), while the opposite site is fixed to a chamber hook. Electrical stimulation field was obtained via two axial platinum wires connected to a stimulator
(LE 12406, 2Biological Instruments, VA, Italy). After equilibration, the preparation was stretched to its optimal length (L0) and tetanic contraction elicited with trains of $350 \mathrm{~ms}$ at increasing frequencies $(10-140 \mathrm{~Hz})$ until maximal force. Eccentric stimulation consisted in a series of $120 \mathrm{~Hz}$ tetani of $500 \mathrm{~ms}$ (spaced by $15 \mathrm{~s}$ ) with a stretch of L0 $10 \%$ at a speed of $1 \mathrm{~L} 0 \mathrm{~s}-1$ during the last $200 \mathrm{~ms}$. The progressive decay in force $v s$ the initial force was measured. Data were analyzed using Dynamic Muscle Analysis Software vs 4.1.6 (ASI). Absolute values of tension have been normalized by cross-sectional area according to standard equations.

\section{RESULTS \\ PDN Restores TJ Occludin and ZO-1 and Glial GFAP Expression in the Mdx Brain}

In the mdx mouse brains, vessels exhibited altered expression of the TJ-associated proteins occludin and $\mathrm{ZO}-1$, but proper expression of the proteins was re-established in the PDNtreated mdx mice. In parallel, glial coverage was reduced in the $\mathrm{mdx}$ vessels with respect to the controls and increased in the PDN-treated mdx brains.

As demonstrated in Figure $1 \mathrm{a}$, on confocal dual immunofluorescence, the control vessels revealed pointed occludin expression along the entire luminal side, which were enveloped by glial processes with intense GFAP staining (Figures $1 \mathrm{a}$ and $2 \mathrm{a}$ ). The $\mathrm{mdx}$ vessels were positive for occludin only along part of the luminal surface, with a linear fluorescence pattern expression (Figure 1b); they were poorly enveloped by GFAP green fluorescence staining of glial processes (Figures $1 \mathrm{~b}$ and $2 \mathrm{~b}$ ).

After PDN treatment, the vessels displayed the characteristic punctuate occludin expression (Figure 1c) on the luminal side, and GFAP glial staining on the abluminal side (Figures 1c and 2c). ZO-1 immunocytochemistry of the $\mathrm{mdx}$ brain demonstrated reduced ZO-1 labeling along the luminal vascular side (Figure 1e) compared with controls (Figure 1d) and an increase in ZO-1 staining, but not ZO-1 membrane organization, after PDN treatment (Figure 1f).

The morphometrical analysis revealed a significant increment of occludin $(4.06 \% \pm 0.12 v s 2.39 \% \pm 0.17, P<0.05)$ and GFAP-labeled areas $(9.67 \% \pm 3.14$ vs $3.98 \pm 2, P<0.05)$ in PDN-treated mice compared with mdx animals (Figure 1g).

Western blot experiments were performed to compare the protein levels of occludin, ZO-1, and GFAP in the three experimental conditions. As shown in Figure 3a, occludin, ZO-1, and GFAP protein levels are reduced in mdx samples, but PDN treatment reinstated their expression. We also examined the phosporylation degree of occludin, which is involved in the BBB permeability, and found increased phosphorylation of occludin in $\mathrm{mdx}$ brains, but occludin phosphorylation was significantly decreased after PDN treatment (Figure 3b). We performed parallel occludin immunoprecipitation, in which reduced occludin expression in $\mathrm{mdx}$ lysates and its recovery in PDN-treated samples were observed (Figure 3b). We also analyzed the levels of mRNA 

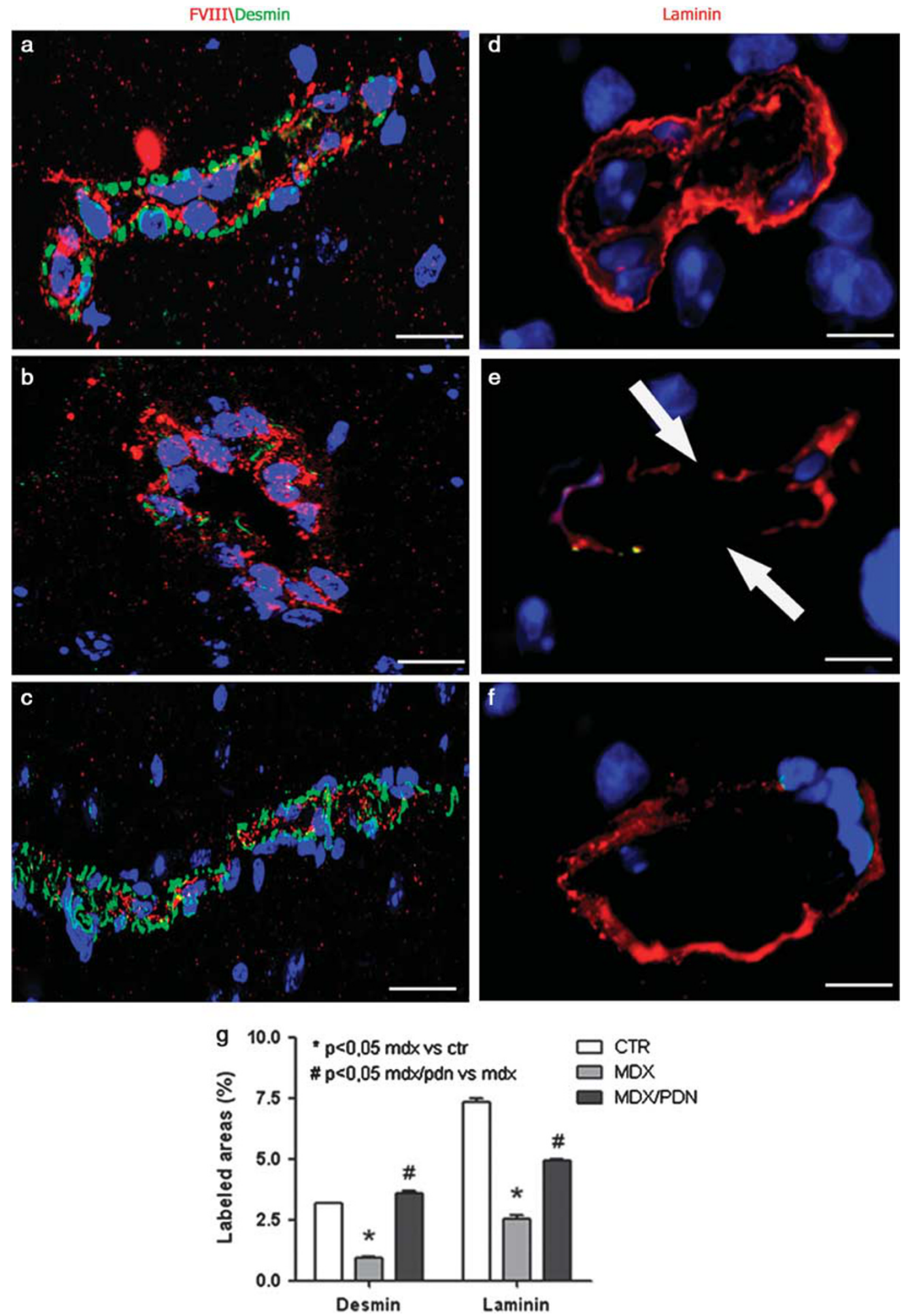

Figure 4 Confocal dual immunofluorescence reaction of FVIII (red) and desmin (green) and laminin in control (a, d), mdx (b, e) and PDN mdx (c, f) vessels, and morphometric analysis of desmin and laminin expression $(\mathbf{g})$. Mdx red-labeled endothelial cells are poorly subtended by a light green fluorescence signal of desmin (b) and by discontinuous laminin fluorescence (e, arrow). Control (a, $\mathbf{d})$ and PDN-treated (c, $\mathbf{f})$ vessels show an intense and pointed desmin green signal $(\mathbf{a}, \mathbf{c})$ and a strong continuous laminin fluorescence $(\mathbf{d}, \mathbf{f})$ subtending the endothelial cells. Scale bar: $\mathbf{a}-\mathbf{c}, 16,6 \mu \mathrm{m} ;$ d-f, $10 \mu \mathrm{m}$. (g) Desmin and laminin expression show a lower value in mdx mice compared with control, while a significant increase in PDN-treated mice compared with the mdx animals is detected. 
a

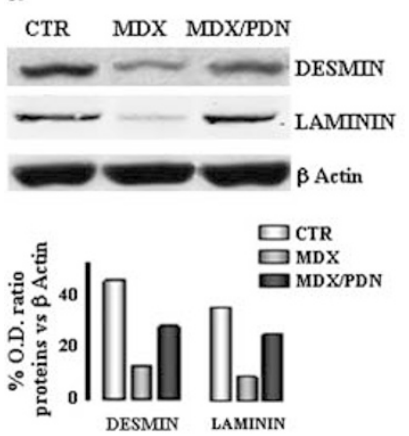

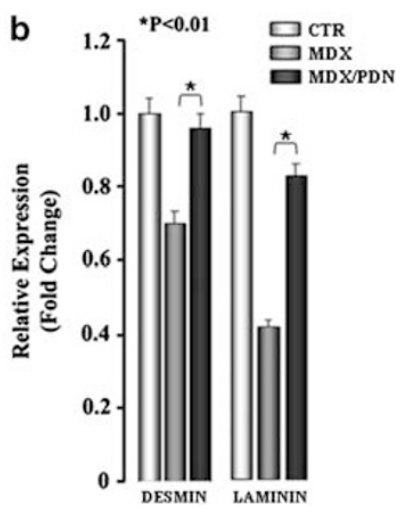

Figure 5 (a) Western blotting analysis of desmin and laminin in the brain homogenates from, respectively, 10 control, $\mathrm{mdx}$, and PDN mdxtreated mice. Their expression levels are decreased in $\mathrm{mdx}$ mice with respect to the controls, but the treatment with PDN restores the protein levels as the control animals. Quantification of the bands reveals a higher level of both proteins in PDN $\mathrm{mdx}$ brain respect to the $\mathrm{mdx}$ animals. The data are representative of three independent experiments from 10 animals for each group. (b) The mRNAs expression analysis by real-time PCR shows a significant downregulation of desmin and laminin mRNA level in the $\mathrm{mdx}$ brain as compared with control animals, while PDN treatment restored the gene expression at the same levels of the control. Data are representative of three independent experiments, from 10 animals for each group. Statistics: Student's $t$-test comparing $\mathrm{mdx}$ mice with wild-type animals as result of the three independent experiments performed in triplicate; ${ }^{*} P<0.01$.

for occludin, ZO-1, and GFAP. Mdx brains displayed reduced levels of occludin, ZO-1, and GFAP compared with the controls, while PDN treatment brought about a return to normal levels of these proteins (Figure $3 \mathrm{c}$ ).

\section{PDN Restores Pericyte Desmin and Basement Membrane Laminin Expression in the Mdx Brain}

Confocal dual immunofluorescence analysis revealed that in mdx mice, endothelial cells (red labeling) were poorly subtended by desmin (green fluorescence, Figure 4b); laminin expression was discontinuous (red fluorescence, Figure 4e), and there were few labeled glial endfeet (Figure 2b). In the PDN-treated mice, like the control animals, desmin staining was intense and pointed (green signal, Figures $4 \mathrm{a}$ and c), and laminin uniformly and completely subtended the endothelial cells (red fluorescence Figures 4d and f), and strongly labeled glial processes encircling the vessel wall (Figures $2 \mathrm{a}$ and $\mathrm{c}$ ).

The morphometrical analysis revealed a significant increase of desmin $(3.06 \% \pm 0.14 v s 0.92 \% \pm 0.11, P<0.05)$ and laminin-labeled areas $(4.91 \% \pm 0.11$ vs $2.53 \% \pm 0.3, P<0.05)$ in PDN-treated mice compared with mdx mice (Figure $4 \mathrm{~g}$ ). To evaluate the protein content and mRNA expression of pericyte desmin and basement membrane laminin in the $\mathrm{mdx}$ brain with or without PDN treatment and in healthy brains, we performed immunoblotting and real-time PCR experiments. The desmin and laminin protein expression was reduced in $\mathrm{mdx}$ brains, but increased after PDN treatment (Figure 5a). In agreement with the previous data, mRNA analysis confirmed the recovery of gene expression in PDN/ $\mathrm{mdx}$ mice compared with the reduced levels in $\mathrm{mdx}$ samples (Figure 5b).

\section{PDN Restores Expression of Glial DAPs AQP4, $\alpha-\beta$ DG and Dp71 Dystrophin in the Mdx Brain}

AQP4 and $\alpha-\beta$ DG were strongly expresssed in perivascular glial endfeet, colocalizing along the entire abluminal vascular side in the control mice (Figures 6a-c; Figures $7 \mathrm{a}-\mathrm{c}$ ), while the expression of these proteins was reduced in the $\mathrm{mdx}$ vessels, with signal found only on the abluminal surface (Figures 6d-f; Figures 7d-f). In parallel, AQP4 colocalized with Dp71 in the glial endfeet in the control vessels (Figures $8 \mathrm{a}-\mathrm{c}$ ), while their expression was reduced, although localizing somewhat, in the $\mathrm{mdx}$ mice (Figure $8 \mathrm{~d}-\mathrm{f}$ ). After PDN treatment, AQP4, $\alpha / \beta$-DG and Dp71 again showed intense vascular expression and colocalization along the vessels (Figures 6g-i; Figures 7g-i; Figures 8g-i).

Morphometric analysis revealed a significant increase of AQP4 $(8.63 \% \pm 0.66 v s 3.06 \% \pm 0.16, P<0.05), \alpha-\mathrm{DG}(4.31 \%$ \pm 0.19 vs $2.99 \% \pm 0.27, P<0.05), \beta$-DG $(3.73 \% \pm 0.16$ vs $1.4 \% \pm 0.17, P<0.05)$, and $\mathrm{Dp} 71$-labeled areas $(6.20 \% \pm 1.09$ vs $1.95 \% \pm 0.35, P<0.05)$ in PDN-treated mice compared with mdx animals (Figure 9a).

Western blotting demonstrated that there were decreased protein levels of Dp71, $\alpha-\beta$ DG and AQP4 in the mdx brain, while PDN treatment induced incremental increases of Dp71 and $\beta$-DG, AQP4, and $\alpha$-DG (Figure 9b). Real-time PCR confirmed that there was a significant downregulation of AQP4 and $\alpha-\beta$ DG in the mdx brain, similar to the findings for protein levels (Figure 9b). In contrast, PDN treatment resulted in gene expression profiles similar to those found in the controls (Figure 9c).

Because AQP4 and $\beta$-DG phosphorylation regulates glial control of water flux important to BBB function, we assessed immunoprecipitates for the phosphorylated forms of AQP4 and $\beta$-DG. Immunoprecipitation of the phosphorylated form of AQP4 and total AQP4 indicated that its phosphorylation was increased in the mdx mouse, while PDN treatment caused a return to normal phosphorylation levels (Figure 9d). Immunoprecipitation of total AQP4 revealed reduced expression in mdx mice after PDN treatment (Figure 9d), and western blotting showed an increase in the phosphorylated form of $\beta$-DG in mdx mice, which returned to normal levels in $\mathrm{mdx} / \mathrm{PDN}$ brains (Figure 9e).

\section{PDN Restores BBB Functionality in the Mdx Brain}

As previously demonstrated ${ }^{14}$, the $\mathrm{BBB}$ of the $\mathrm{mdx}$ brain showed remarkable permeability. After HRP injection, numerous and extensive perivascular areas of HRP escape were observed in the mdx brain (Figure 10b), whereas after PDN treatment, the vascular permeability was reduced and the marker was exclusively located in the vessel lumen (Figure 10c), as in the control brain (Figure 10a). 
AQP4|alfaDystroglycan

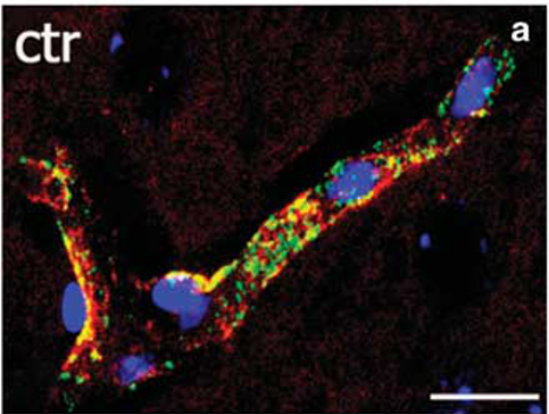

a
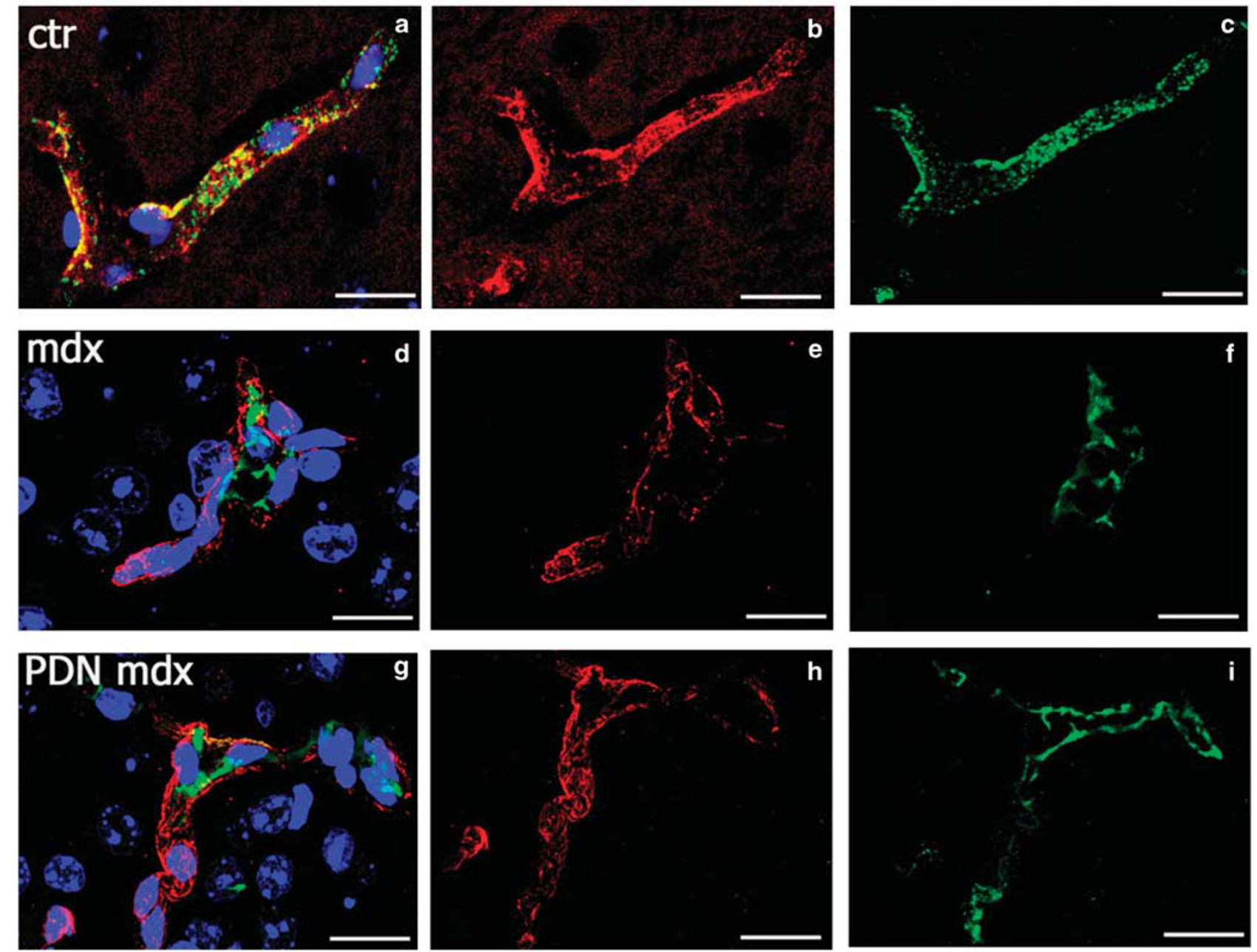

Figure 6 Confocal dual immunofluorescence reaction of AQP4 (red) and $\alpha$-DG (green) in control (a-c), mdx (d-f), and PDN mdx (g-i) vessels. Control $(\mathbf{a}-\mathbf{c})$ and PDN $\mathrm{mdx}(\mathbf{g}-\mathbf{i})$ vessels show an intense AQP4 and $\alpha$-DG colocalization along the entire abluminal vascular side, while the mdx vessels show a separate and reduced fluorescence signal (d-f). Scale bar: $\mathbf{a}-\mathbf{i}, 25 \mu \mathrm{m}$.

\section{PDN Restores DAPs, AQP4, $\alpha-\beta$ DG, Laminin and Utrophin Expression in Mdx Muscle Fibers: Outcome on Pathology-Related Parameters}

In the GC muscular fibers, we observed intense AQP4 and $\alpha-\beta$ DG staining of the sarcolemma of control fibers (green signal; Figure 11a for $\alpha$-DG; Figure 11d for $\beta$-DG; Figure 11g for AQP4), but the mdx fibers were either faintly labeled or negative (Figures $11 \mathrm{~b}$, e and $\mathrm{h}$ ). PDN treatment reestablished AQP4 and $\alpha-\beta$ DG sarcolemmal staining (Figures $11 \mathrm{c}$, $\mathrm{f}$ and i). Confocal immunofluorescence of $\mathrm{mdx}$ GC muscle exhibited faint and discontinuous expression of laminin around the sarcolemma of myofibers (Figure 12b), while control animals exhibited intense fluorescence (Figure 12a). Interestingly, PDN-treated mice showed a strong laminin expression around the myofibers, similar to controls (Figure 12c).

The mdx myofibers showed faint and discontinuous utrophin staining of the sarcolemma (Figure 13b), while in the control animals, light membrane utrophin expression was recognizable (Figure 13a). PDN treatment led to a marked sarcolemmal expression of utrophin (Figure 13c).

Real-time PCR demonstrated a significant downregulation of AQP4 and $\alpha-\beta$ DG mRNAs in mdx muscular fibers. PDN treatment re-established the gene expression at control levels (Figure 14a). Interestingly, we found that, as in brain, in the CG muscles the P-AQP4 and phosho- $\beta$-DG levels were increased in the mdx mice, and that PDN treatment markedly reduced their phoshorylation (Figures $14 \mathrm{~b}$ and c). The immunoprecipitation of total AQP4 (Figure 14b) reveals that the same trend was observed in the GC (Figure 14a) and in the brain (Figure 9c). It was therefore important to determine whether the structural changes observed in the muscles of the PDN-treated $\mathrm{mdx}$ mice exhibited in vivo and ex vivo markers of muscle pathology and sarcolemmal stability.

In line with previous observations, ${ }^{36,39} \mathrm{PDN}$-treated $\mathrm{mdx}$ mice showed stronger forelimb force when compared with untreated counterparts. Ex vivo, a partial but significant 

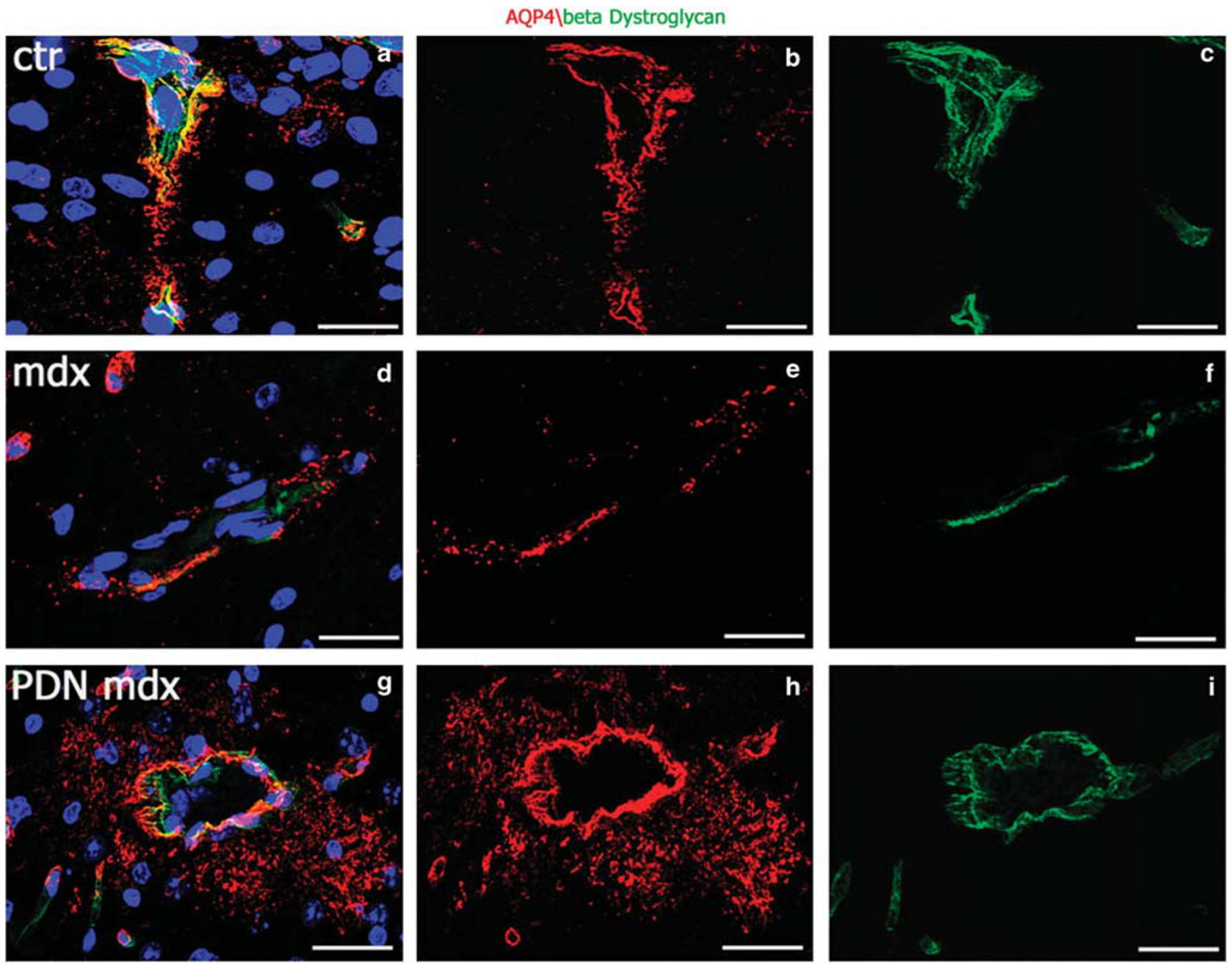

Figure 7 Confocal dual immunofluorescence reaction of AQP4 (red) and $\beta$-DG (green) in control (a-c), mdx (d-f), and PDN mdx (g-i) vessels. Control $(\mathbf{a}-\mathbf{c})$ and PDN mdx ( $\mathbf{g}-\mathbf{i})$ vessels show an intense orange fluorescence signal of colocalization along the entire abluminal side, instead the mdx vessels show a reduced expression and separate AQP4 and $\beta$-DG signal for some tract of the abluminal surface (d-f, arrow). Scale bar: a-i, $25 \mu \mathrm{m}$.

increase in the tetanic force of EDL muscle was observed; this novel effect paralleled the already described amelioration of the rheobase voltage for muscle contraction (Table 2). Importantly, we also monitored, for the first time, the impact of PDN treatment on force loss during lengthening contraction, an index of sarcolemma fragility, along with the classical parameter, levels of plasma CK. Neither eccentric contraction nor CK was ameliorated by the PDN treatment. Thus, in spite of the decrease in the signs of degeneration, and a parallel improvement of muscle performance, there was limited effect on sarcolemmal stability. ${ }^{36}$

\section{DISCUSSION}

Glucocorticoids are clinically used in DMD patients, although the mechanisms underlying its efficacy are little understood. The functional amelioration observed in both patients and mdx mice is likely the result of drug action on different pathways, including inflammation and oxidative stress, ${ }^{36,43,44}$ fiber regeneration and differentiation, ${ }^{45,46}$ and reduction of necrosis with parallel amelioration of calcium homeostasis. ${ }^{36,47}$ There is little evidence available in dystrophic patients about the possible impact of corticosteroids on the brain.

This study is the first parallel evaluation of the effect of PDN on both the brain and muscle of the dystrophic mdx mouse, disclosing the drug's ability to similarly modulate the expression of key components of the dystrophinglycoprotein complex in the two organs.

In the brain we have demonstrated that PDN treatment leads to a significant increase of mRNA and protein content of $\mathrm{BBB}$ markers, and a reduction of the degree of phosphorylation of occludin, AQP4, and $\beta$-DG. These changes paralleled an increase of protein levels of Dp 71, and mRNA and protein levels of the AQP $4 / \alpha-\beta$ DG complex, which restored the functional relationship between the glial intracellular cytoskeleton and the extracellular matrix.

Moreover, we found that the reestablishment of the $\mathrm{BBB}$ marker and DAP proteins in the PDN-treated mdx mice 

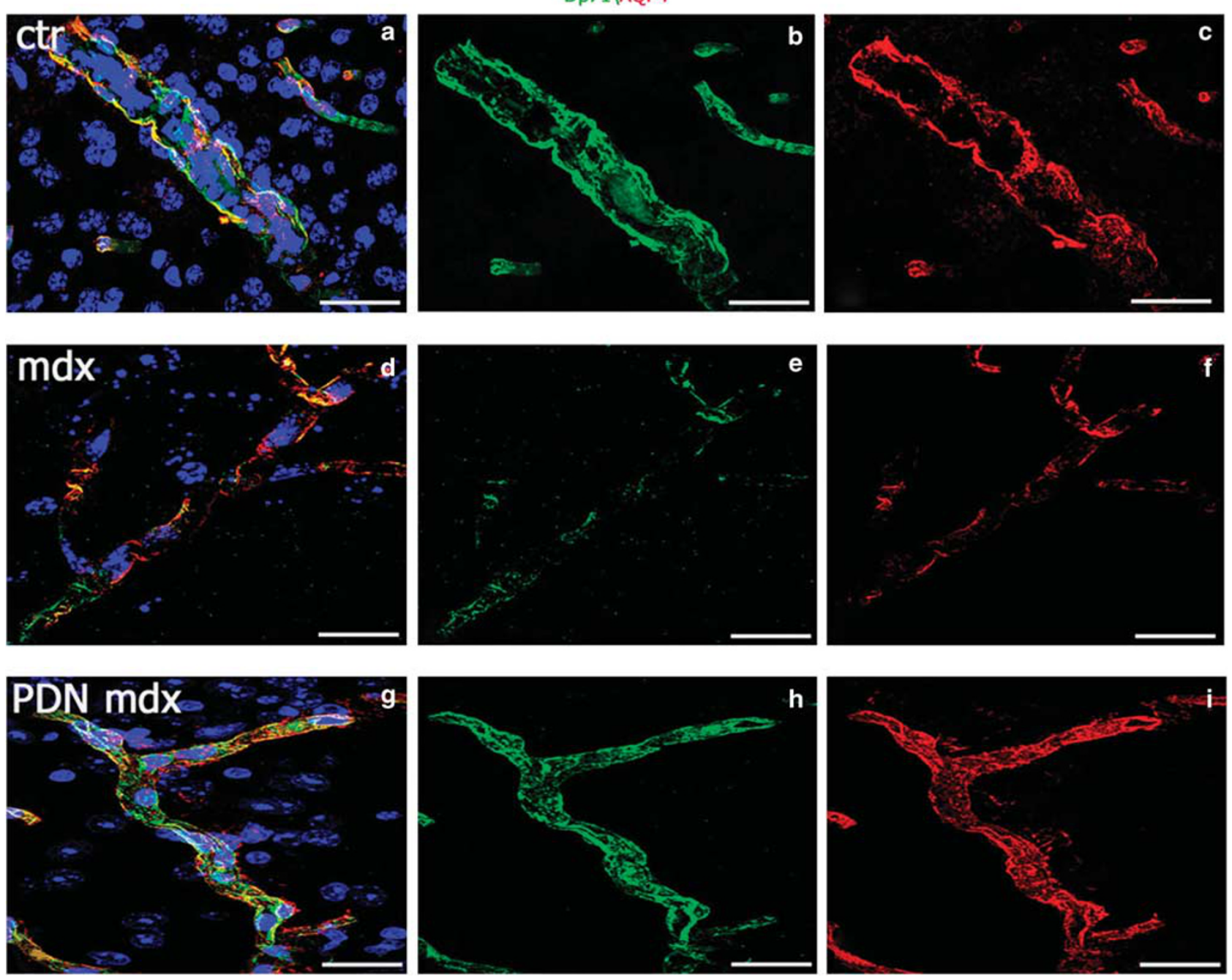

Figure 8 Confocal dual immunofluorescence reaction of Dp71 (green) and AQP4 (red) in control (a-c), mdx (d-f), and PDN mdx (g-i) vessels. Control $(\mathbf{a}-\mathbf{c})$ and PDN mdx ( $\mathbf{g}-\mathbf{i})$ vessels show a strong orange signal of Dp71 and AQP4 colocalization in the perivascular glial endfeet, while the mdx vessels (d-f) show a reduced expression of both proteins. Scale bar: $\mathbf{a}-\mathbf{i}, 25 \mu \mathrm{m}$.

correlated with the restoration of BBB functionality. In contrast to $\mathrm{mdx}$ brains, which exhibited perivascular HRP escape with significant vascular permeability and altered marker localization, the vessel lumina of the PDN-treated mdx mice looked like the controls.

Interendothelial TJs, pericytes and perivascular glial endfeet forming the glio-vascular units are responsible for the integrity of the BBB. ${ }^{48}$ The main molecular components of the TJs are transmembrane proteins, as occludin and claudins link to adaptor cytoplasmic proteins such as ZO-1. ${ }^{49-51}$ For both occludin and ZO-1, phosphorylation levels help regulate barrier permeability, ${ }^{52-54}$ and increased paracellular permeability associated with the tyrosine phosphorylation, and dissociation of occludin and ZO-1 from the cytoskeleton can be caused by oxidative stress. ${ }^{55}$ Furthermore, vascular endothelial growth factor (VEGF) can increase intercellular permeability by enhancing ZO-1 and occludin phosphorylation, causing displacement and the reduction of $\mathrm{ZO}-1$ expression, ${ }^{56,57}$ corroborating the role of a tyrosine kinasedependent mechanism for the association of the junctional complex to cytoskeleton.

Accordingly, in the brain of $\mathrm{mdx}$ mice, some vascular permeability is recognizable due to alteration of TJs, such as the detachment of their external leaflet membrane, altered expression of claudin-1 and ZO-1, and increased phosphorylation of ZO-1. ${ }^{14,58}$ In this study, we found that all these changes are targeted by the PDN treatment, which restores the morphological banded expression of both $\mathrm{ZO}-1$ and occludin, presumably due to an increase in their mRNA levels and a reduction of the degree of phosphorylation of occludin.

It is well accepted that glucocorticoids reinforce the TJs and increase the barrier properties of brain capillary endothelial cells by enhancement of ZO-1 and occludin. In fact, binding of the activated glucocorticoid receptor to putative glucocorticoid-responsive elements in the occludin promoter 
a

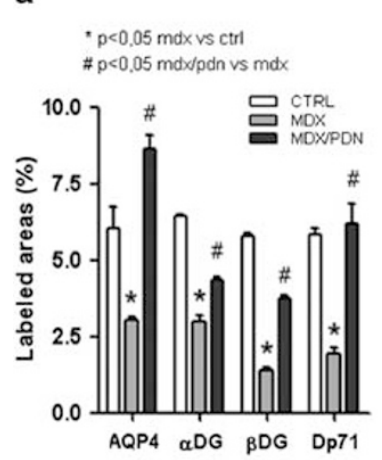

c

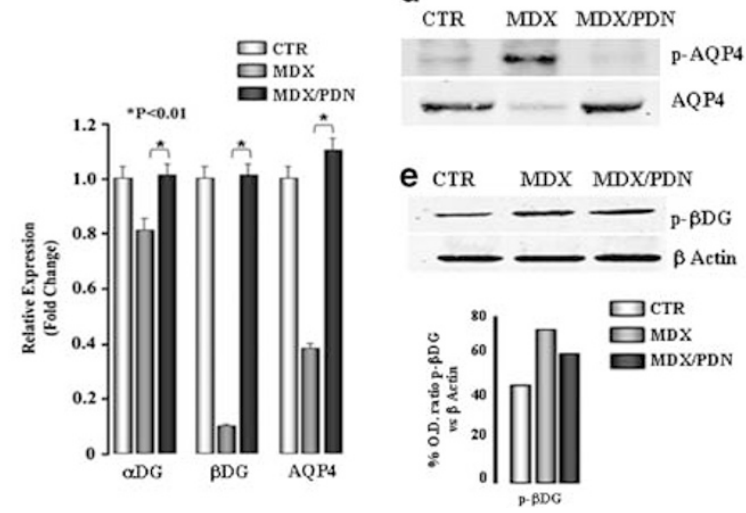

Figure 9 (a) Morphometric analysis of AQP4, $\alpha / \beta$ DG and DP71 expression show a lower value in $\mathrm{mdx}$ mice compared with control, while a significant increase in PDN-treated mice compared with the $\mathrm{mdx}$ animals is detected. (b) Western blotting analysis of $\alpha-\beta$ DG, AQP4, and Dp71 in brain samples from, respectively, 10 control, mdx, and PDN mdxtreated mice shows a lower levels of the proteins in $\mathrm{mdx}$ mice compared with controls. The treatment with PDN shows a partial increment of the protein levels. Densitometric analysis of the bands shows a higher level of all the proteins in PDN mdx brain respect to the $\mathrm{mdx}$ animals. The data are representative of three independent experiments from 10 animals for each group. (c) The real-time PCR carried out on control, $\mathrm{mdx}$, and PDN-treated samples shows the decreased expression of $\alpha-\beta$ DG and AQP4 mRNAs in mdx samples, and their recovery after PDN administration. Data are representative of three independent experiments, from 10 animals for each group. Statistics: Student's $t$-test comparing $\mathrm{mdx}$ mice with wild-type animals as result of the three independent experiments performed in triplicate; ${ }^{*} P<0.01$. (d) The immunoprecipitate of phosphorylated forms of AQP4 shows its increased level in $\mathrm{mdx}$ mice respect to the controls, and the reduction in the $\mathrm{mdx}$ mice after PDN treatment. The immunoprecipitation of total AQP4 executed as control, shows a similar result to that found in western blotting of panel $\mathbf{b}$. (e) The western blotting for the analysis for phosphorylated $\beta$-DG form and its respective densitometry shows its increased level in $\mathrm{mdx}$ brains respect to the controls and the decreasing in PDN-treated mice.

has been described. ${ }^{38,59,60}$ Dexamethasone prevents alteration of TJ-associated proteins in bacterially infected epithelial choroidal cells by restoring the occludin phosphorylation degree via attenuation of ERK activation and MMP-3 expression. ${ }^{61}$ It is noteworthy that the inhibition of the ERK pathways blocks the production of MMPs, which in
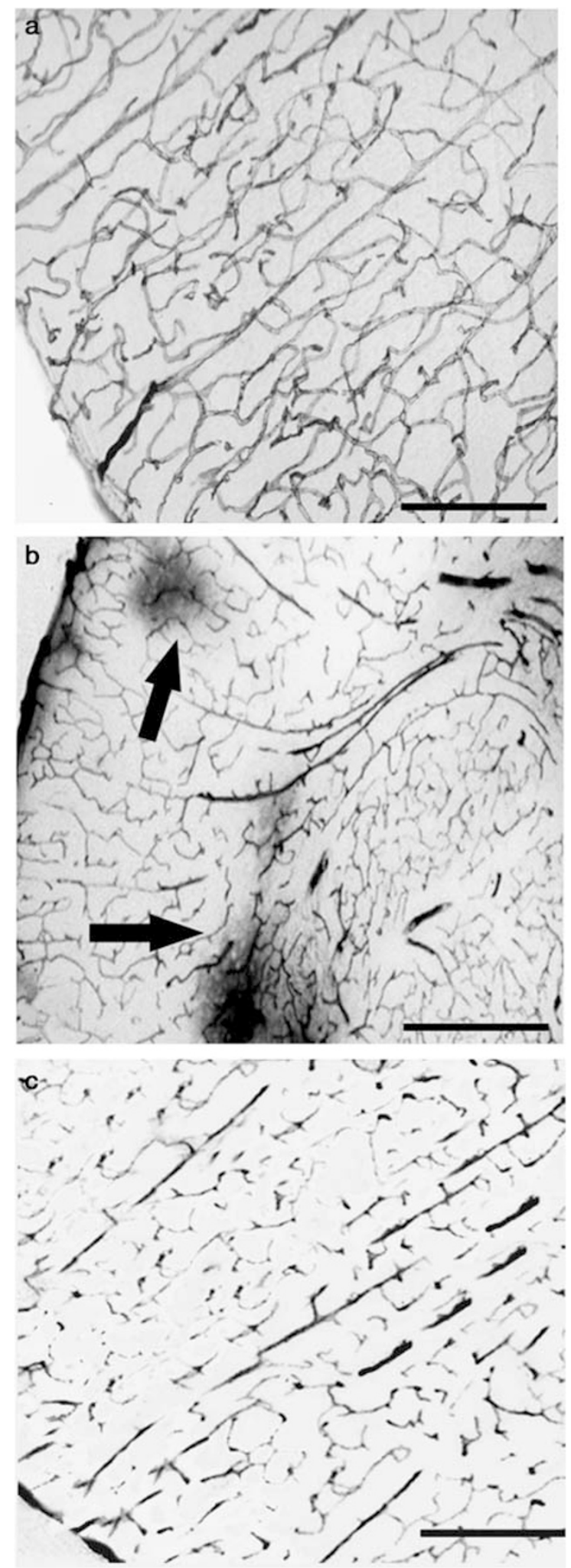

Figure $10 \mathrm{HRP}$ cytochemical localization in the brain of control (a), mdx (b), and PDN mdx mice (c). (a) Control vessels showing an intravascular localization of the marker, note the neuropile unlabeled. (b) Mdx mouse showing a vascular network with large areas of perivascular HRP escape (arrow). (c) PDN mdx vessels showing the HRP marker exclusively located in the vessel lumina. Scale bars: a, $50 \mu \mathrm{m}, \mathbf{b}, \mathbf{c}, 66,6 \mu \mathrm{m}$. 

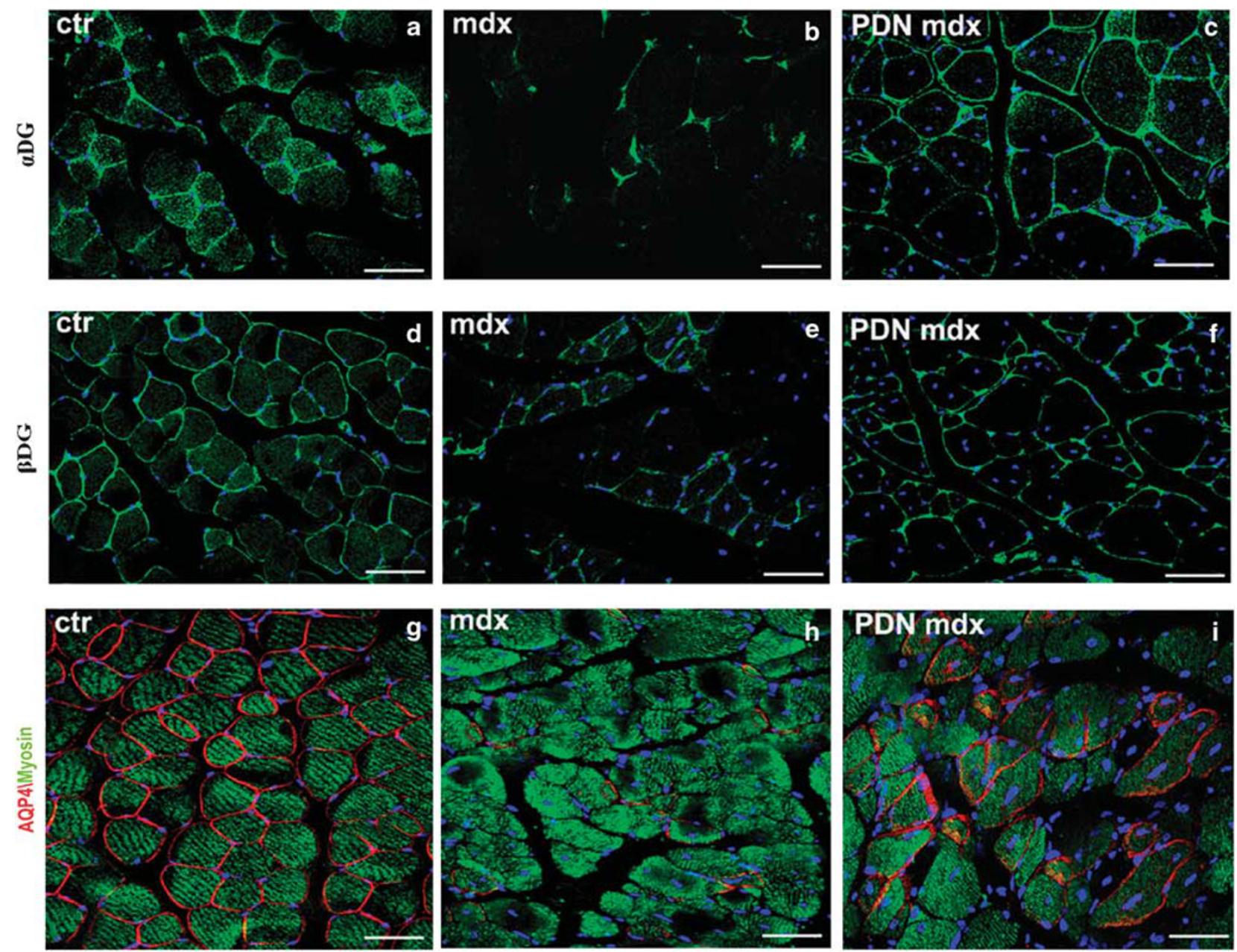

Figure 11 Confocal dual immunofluorescence reaction of $\alpha$-DG (green), $\beta$-DG (green), AQP4 (red), and myosin (green) in control (a, d, $\mathbf{g}$ ), mdx (b, e, $\mathbf{h}$ ), and PDN mdx (c, $\mathbf{f}, \mathbf{i}) \mathrm{GC}$ muscles. The control myofibers show a higher $\alpha / \beta$ DG green $(\mathbf{a}, \mathbf{d})$ and AQP4 (g) red fluorescence at sarcolemma compared with the $\mathrm{mdx}(\mathbf{b}, \mathbf{e}, \mathbf{h})$ faintly labeled myofibers. On the contrary, the PDN mdx fibers display a restoring of an intense fluorescence signal for $\alpha / \beta$ DG (c, f) and AQP4 (i). Scale bar: $\mathbf{a}-\mathbf{i}, 25 \mu \mathrm{m}$.

turn cleave occludin in the epithelial cells after induced apoptosis. ${ }^{62}$ Moreover, glucocorticoids protect the distribution and expression of $\mathrm{ZO}-1$ and actin induced by hypoxia, ${ }^{63}$ and prevent the cytokine-induced expression of matrix metalloproteinase-9 (MMP-9) and ZO-1 alteration. ${ }^{28}$ Furthermore, they induce downregulation of VEGF and decrease occludin phosporylation in blood-retinal barrier by reducing PKC $^{64}$ activation. $^{64,65}$

We previously reported that in mdx mice, VEGF overexpression induced by hypoxia inducible factor- $1 \alpha$ (HIF- $1 \alpha$ ) activation, coupled with MMP-2 and -9 , activates secretion and upregulates ZO-1 phosphorylation. ${ }^{58}$ Overall, our results suggest that the PDN could restore ZO-1 and occludin TJ expression in the dystrophic brain by acting directly, or indirectly, via VEGF and MMPs blocking protein kinase activation of ZO-1 and occludin.

Another effect of PDN treatment in the brain of the mdx mouse is the re-expression of pericyte marker desmin and the glial marker GFAP, both of which were downregulated in mdx mice. ${ }^{12,14}$ It was noted that astrocytes and pericytes interact with the endothelial cells in maintaining the vessel's barrier features and junctional tightness. ${ }^{66}$

Pericytes express glucocorticoid receptors, ${ }^{67}$ and glucorticoids are able to upregulate occludin, claudin-5, and ZO-1 in cultured endothelial cells, but only in the presence of astrocytes and pericytes. Because of this finding, our results suggest a role for these two types of cells in glucorticoid responsiveness in the brain. ${ }^{60}$

AQP4 is important for the integrity of BBB function, and its expression on the perivascular glial endfeet is altered in pathological brain conditions. ${ }^{68-70} \mathrm{AQP} 4$ is dynamically regulated in different ways. Phosphorylation decreases permeability when phosphorylation occurs at Ser180, ${ }^{26,71}$ but in contrast, phosphorylation increases permeability when Ser111 is phosphorylated by PKG. ${ }^{72}$ It is thought that Ser180, a consensus site for PKC, is localized in a cytosolic loop of AQP4, and is a target residue for PKC-mediated phosphorylation of AQP4. There is no evidence of a direct 


\section{Laminin}
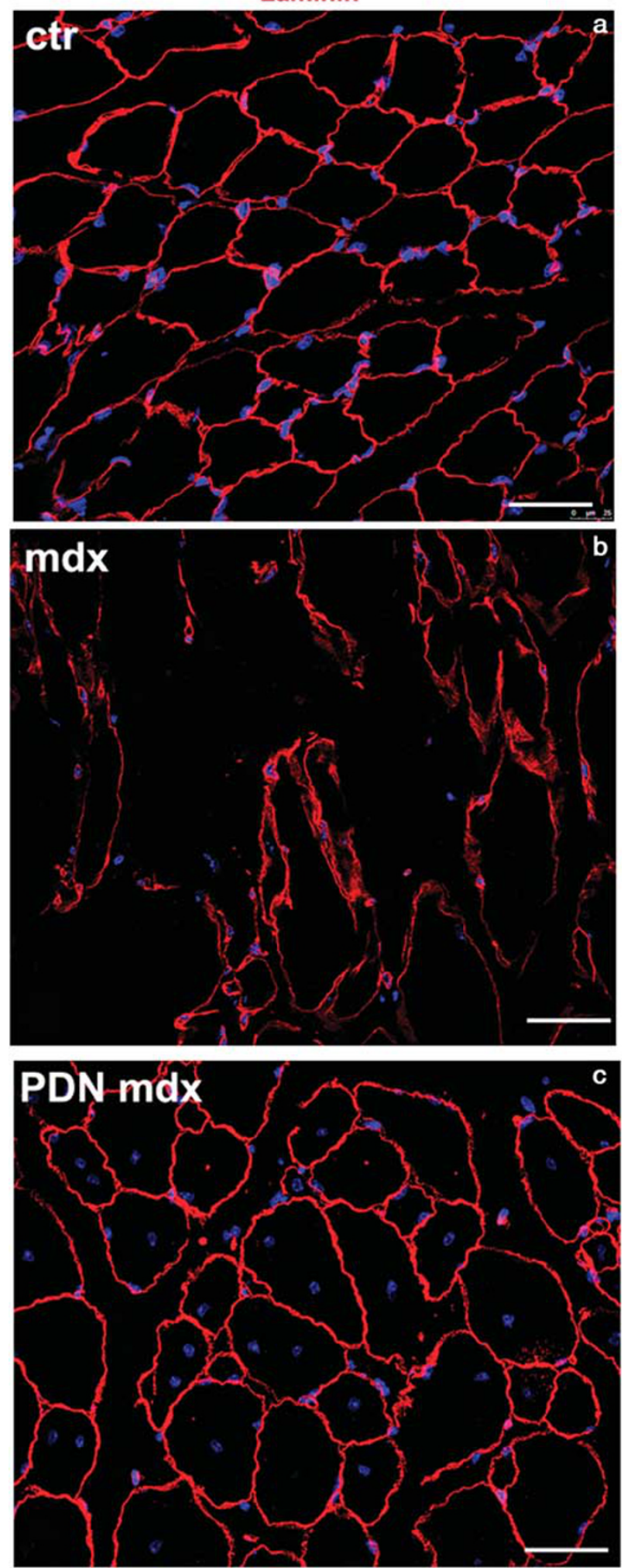

Figure 12 Confocal immunofluorescence reaction of laminin (red) in control (a), mdx (b), and PDN mdx (c) muscles. Mdx myofibers show a faint and discontinuous expression of laminin around the sarcolemma (b) compared with control animals, which express an intense sarcolemmal red signal (a). PDN mdx myofibers again show a strong laminin expression (c). Scale bar: a-c, 15, $8 \mu \mathrm{m}$.
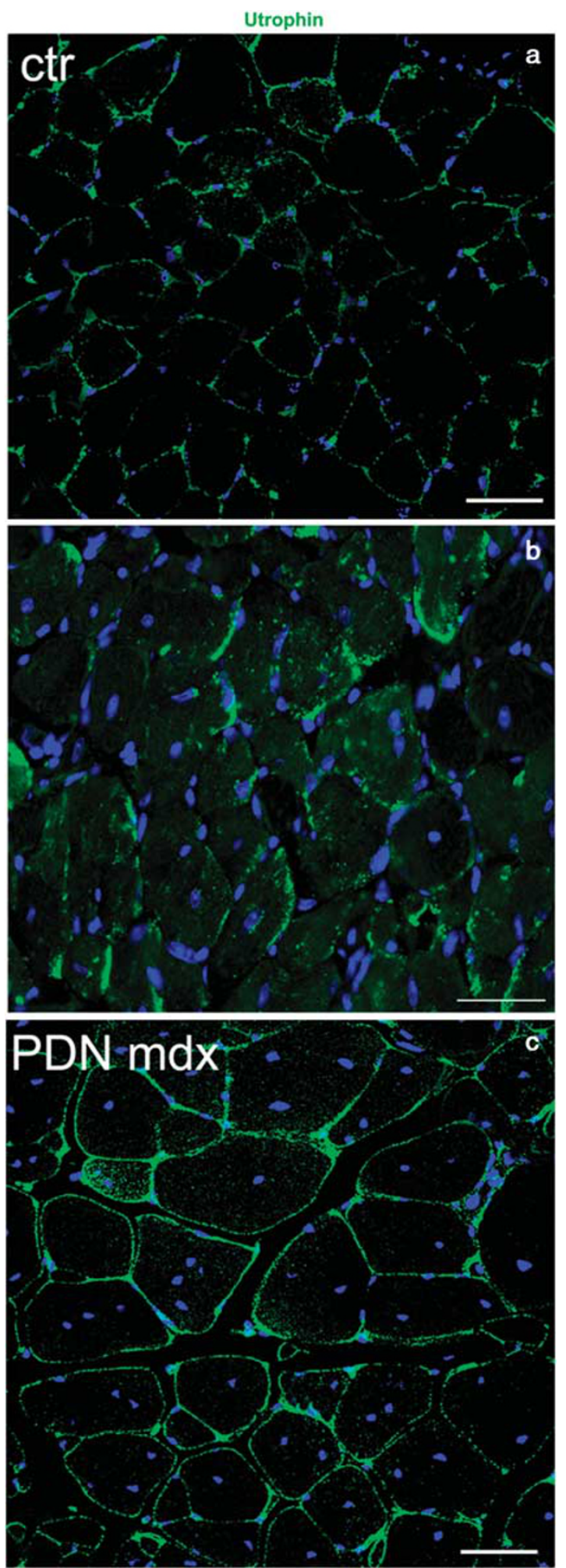

Figure 13 Confocal immunofluorescence reaction of utrophin (green) in control (a), $\mathrm{mdx}(\mathbf{b})$, and PDN $\mathrm{mdx}$ (c) muscles. Control myofibers show a light membrane utrophin expression (a), while the $\mathrm{mdx}$ animals show a faint and discontinuous green fluorescence on the sarcolemmal level, and PDN myofibers display an intense sarcolemmal fluorescence urtophin signal (c). Scale bar: a-c, $25 \mu \mathrm{m}$. 
phosphorylation of AQP4 by PKC in primary cultured astrocytes, although endogenous mouse AQP4 is constitutively phosphorylated..$^{73,74}$ a

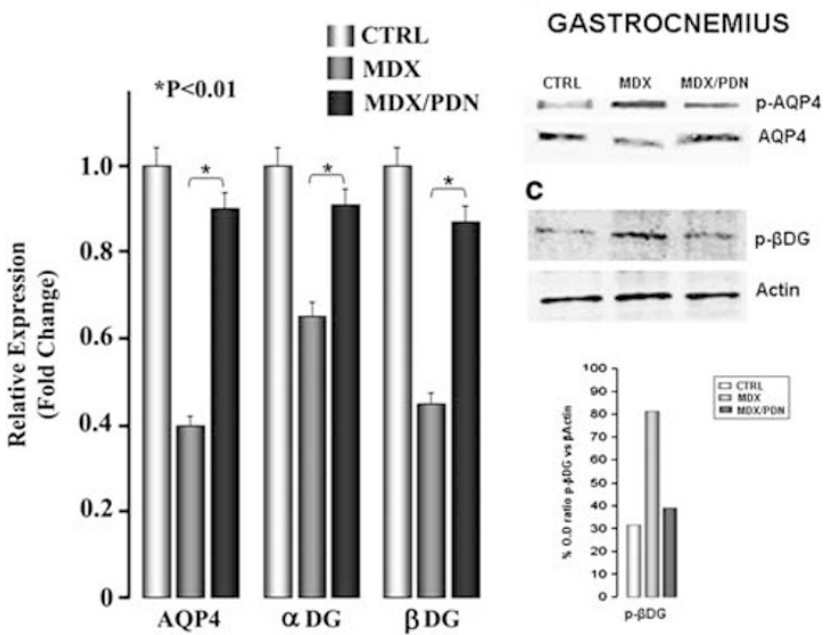

Figure 14 (a) The mRNA analyses of gastrocnemius lysates demonstrate the reduced AQP4 and $\alpha-\beta$ DG levels in mdx mice as compared with the controls, and their enhanced levels in the mdx mice treated with PDN.

(b) The immunoprecipitate of phosphorylated forms of AQP4 shows an increment in $\mathrm{mdx}$ mice respect to the controls and a reduction of its phosphorylation degree in the $\mathrm{mdx}$ mice after PDN treatment. The total AQP4 immunoprecipitation shows the reduction of AQP4 levels in mdx mice samples and the recovery in PDN-treated animals. (c) Immunoblotting analysis of the P- $\beta$ DG and quantification of the bands, show an increase in the mdx mice compared with controls. PDN treatment reduced its phosphorylation state. Data are representative of three independent experiments, from animals for each group.Statistics: Student's $t$-test comparing $\mathrm{mdx}$ mice with wild-type animals as result of the three independent experiments performed in triplicate; ${ }^{*} P<0.01$.
Our experiments reveal that the PDN treatment restores the normal level of both AQP4 content and its phosphorylated form, while the pathological condition is characterized by an increase in AQP4 phosphorylation and low protein levels. These data suggest the effects of PDN in BBB repair may be mediated by a reduction in AQP4 phosphorylation, which in turn allows its correct anchoring on the glial membrane, restoring a normal flux.

Finally, we have demonstrated that PDN treatment can induce restoration of the DAPs $\alpha-\beta$ DG and normalize $\beta$-DG phosporylation and Dp71 expression on glial endfeet, all of which are profoundly altered in the $\mathrm{mdx}$ brain. We also noted the translocation of $\alpha-\beta$ DG in the glial cytoplasmic endfeet, coupled with a significant reduction of laminin and DAPs, such as AQP4, Kir 4.1, syntrophin, and Dp 71.68

AQP4 is connected to the short dystrophin Dp71, ${ }^{18}$ and is coexpressed with $\alpha-\beta$ DG proteins ${ }^{22}$, which in turn are receptors for the basement membrane laminin and agrin. ${ }^{75}$ In the retina of Dp71 null mice, AQP4 was reduced ${ }^{76}$, and glial AQP4 and Dp71 decreased in parallel during mdx BBB development. $^{12}$

Moreover, the phosphorylation of $\beta$-DG was involved in the adhesion in skeletal muscle fibers ${ }^{27}$ and DGs were downregulated in the muscle fibers and brains of DMD patients and $\mathrm{mdx}$ mice. ${ }^{77-79}$ In addition, altered $\alpha$-DG glycosylation, and aberrant AQP4 and potassium channel Kir 4.1 location in perivascular domains have been reported in an animal model of dystroglycanopathies, ${ }^{80}$ supporting the role of a correct link between the extracellular matrix and DAPs in the clustering of the channel proteins.

Furthermore, in our study we have detected a different pattern between the $\alpha$-DG gene expression and its protein level in the mdx mice, and we found that PDN treatment

Table 2 Effect of a-methyl-prednisolone treatment on in vivo and ex vivo pathology signs of mdx mouse

\begin{tabular}{|c|c|c|c|c|c|c|c|}
\hline & BW (g) & Fmax (kg) & FNmax & $\begin{array}{l}\text { EDL sP0 } \\
\left(k N / m^{2}\right)\end{array}$ & $\begin{array}{l}\text { EDL rheobase } \\
\text { voltage }(\mathrm{mV})\end{array}$ & $\begin{array}{c}\% \text { Drop force } \\
\text { eccentric contraction }\end{array}$ & CK (U/I) \\
\hline $\mathrm{WT}(n=6)$ & $27,8 \pm 0.4$ & $0.225 \pm 0.007$ & $8.1 \pm 0.24$ & $127.5 \pm 12$ & $-68 \pm 1.4$ & $-0.36 \pm 1.43$ & $2696 \pm 1766$ \\
\hline MDX + vehicle $(n=7)$ & $25.4 \pm 0.97^{\mathrm{a}, \mathrm{b}}$ & $0.135 \pm 0.005^{\mathrm{a}, \mathrm{b}}$ & $5.4 \pm 0.3^{a, b}$ & $87.7 \pm 6.0^{\mathrm{a}, \mathrm{b}}$ & $-75.3 \pm 1.4^{\mathrm{a}, \mathrm{b}}$ & $-8.84 \pm 1.84^{b}$ & $17363 \pm 4576^{a, b}$ \\
\hline $\operatorname{MDX}+\operatorname{PDN}(n=9)$ & $24.4 \pm 0.5^{\mathrm{a}, \mathrm{b}}$ & $0.159 \pm 0.01^{a, b}$ & $6.6 \pm 0.3^{a, b, c}$ & $108.3 \pm 4.8^{c}$ & $-72 \pm 1.2^{\mathrm{a}, \mathrm{b}, \mathrm{c}}$ & $-13.17 \pm 9.34$ & $14807 \pm 2441^{a, b}$ \\
\hline
\end{tabular}

Values are means \pm s.e.m. from the number of animals in parentheses. Experimental groups of mice are as follows: wild type (WT), exercised mdx mice treated with vehicle (sterile water; vehicle), and exercised mdx mice treated with PDN $1 \mathrm{mg} / \mathrm{kg}$ (PDN). The in vivo parameters, measured after 4 weeks of exercise and treatment, are the following: BW, body weight (in g); Fmax, maximal forelimb strength (in kg); and FNmax, the normalized forelimb strength calculated for each mouse by normalizing Fmax for body weight. Ex vivo parameters included functional recordings on extensor digitorum longus (EDL) muscle. For contraction measurement the maximal isometric tetanic force $\left(\mathrm{pPO}\right.$ in $\mathrm{kN} / \mathrm{m}^{2}$ ) and the percentage of force drop during eccentric contraction, measured at the 5 th pulse train vs the first one are shown. For the electrophysiological experiments, it is shown the rheobase voltage ie the membrane voltage at, which contraction occurs independently on depolarizing pulse duration (in $\mathrm{mV}$ ). As biochemical index plasma creatine kinase activity (CK in U/l) has been measured by standard spectrophotometric analysis. A statistical difference by ANOVA test was found for BW $(\mathrm{F}>6 ; P<0.009)$, Fmax $\left(\mathrm{F}>25 ; P<3.9 \times 10^{-6}\right)$, FNmax $\left(\mathrm{F}>17 ; P<4.6 \times 10^{-5}\right)$, EDL sP0 $(\mathrm{F}>6.2$; $P<0.009)$, EDL Reobase Voltage $(\mathrm{F}>6 ; P<0.008)$ and $\mathrm{CK}(\mathrm{F}>5 ; P<0.02)$

Post-hoc Bonferroni t-test is as follows:

${ }^{\text {a }}$ Significantly different with respect to wt mice: $0.03<P<1.2 \times 10^{-6}$.

The statistical significance by Student's $t$-test is as follows:

${ }^{b}$ Significantly different with respect to wt mice: $0.05<P<0.001$.

'Significantly different with respect to vehicle-treated mdx mice: $0.05<P<0.02$.

Statistical significance for fitted rheobase voltage has been calculated on number of fibers determining the fit as described elsewhere. ${ }^{11}$ 
induced a total recovery of $\alpha$-DG mRNA increment, but a partial recovery of the functional protein level. Many posttranslational modifications of newly synthesized $\alpha$-DG have been described, including glycosylation, ${ }^{81,82}$ and the glucocorticoids are known to modulate the glycosylation of many proteins. ${ }^{83}$ Our results suggest that the $\alpha$-DG alteration in mdx animals may involve post-translational events rather than gene expression.

Overall, these data indicate that PDN reverses the $\mathrm{BBB}$ alterations found in mdx mice. The reduction in AQP4 and occludin phosphorylation, coupled with their anchoring to glial and endothelial membranes in the PDN-treated mice, suggests that the glial and endothelial cells may be the targets of the drug in the brain. Finally, the enhanced expression of AQP4 and $\alpha-\beta$ DG in the brain, coupled with an increase in laminin and reduced phosphorylation $\beta$-DG, suggest that PDN might ameliorate the cerebral pathology in the $\mathrm{mdx}$ mouse, restoring the correct interactions between DAP proteins and the extracellular matrix through protein kinase modulation.

It is noteworthy that PDN exerted similar effects in muscle, leading to a marked increase in $\alpha-\beta \mathrm{DG}, \mathrm{AQP} 4$, laminin, and utrophin. The ability of PDN to upregulate utrophin is well known; the underlying mechanism involves both enhanced NF-AT transcription and translation. ${ }^{27,84}$ Utrophin might act as a surrogate for dystrophin and associate with $\beta$-DG to rescue the complex. ${ }^{84} \mathrm{~A}$ critical tyrosine residue of $\beta$-DG is exposed in the absence of dystrophin, and the consequent phosphorylation contributes to internalization and ubiquitin -related degradation of $\beta$-DG. Nonetheless, bortezomib, a proteasome inhibitor, has been found to increase the expression of dystrophin-glycoprotein complex in muscles of mdx mice and in DMD biopsies. ${ }^{27,85}$ Mutation of the critical tyrosine residue also leads to enhanced expression of sarcolemmal $\beta$-DG; ${ }^{27}$ perhaps the utrophin- $\beta$-DG association masks the tyrosine, thus reducing its phosphorylation and consequent $\beta$-DG degradation. The stabilization of $\beta$-DG may salvage the complex and anchor AQP4 to laminin at the extracellular matrix. Other mechanisms cannot be ruled out, but more detailed analysis is necessary concerning the possible effect of PDN on other pathways.

However, the functional outcome of the above-described amelioration, at least at skeletal muscle level, is not clear. The fact that the association of utrophin, $\alpha-\beta$ DG, and laminin does not stabilize sarcolemma is puzzling, although it is consistent with previous studies; PDN treatment does not reduce the high plasma level of CK, a marker of leaky sarcolemma. However, we present the novel result that PDN does not prevent force drop during lengthening contraction. However, the PDN treatment does lead to the amelioration of other anomalies, in line with previous studies. ${ }^{36,39}$ The partial protection offered by PDN may be related to its wide pharmacological effects. We cannot rule out the theory that in skeletal muscle, the replacement of dystrophin with utrophin leads to a different quaternary structure and function from those in the brain. It is also known that a large amount of utrophin needs to be expressed in order to have a significant effect, an observation that needs to be taken into account when looking for a correlation between structural and functional outcome. ${ }^{78}$

In conclusion, these results allow us to gain insight into the mechanism by which PDN acts on dystrophin-deficient muscle and brain, providing new information towards the understanding of its clinical efficacy and for the identification of novel drug targets for DMD.

\section{ACKNOWLEDGEMENTS}

The support of the Duchenne Parent Project The Netherland (DPP-NL) to ADL is gratefully acknowledged.

\section{DISCLOSURE/CONFLICT OF INTEREST}

The authors declare no conflict of interest.

1. Grounds MD, Radley HG, Lynch GS, et al. Towards developing standard operating procedures for pre-clinical testing in the $\mathrm{mdx}$ mouse model of Duchenne muscular dystrophy. Neurobiol Dis 2008;31:1-193.

2. Muntoni F, Mateddu A, Serra A. Passive avoidance behaviour deficit in mdx mouse. Neuromusc Disorders 1991;1:121-123.

3. Meheler MF. Brain dystrophin, neurogenetics and mental retardation. Brain Res Brain Res Rev 2000;32:277-307.

4. Crosbie $\mathrm{RH}$, Heighway J, Venzke DP, et al. Sarcospan, the 25-kDa transmembrane component of the dystrophin-glycoprotein complex. J Biol Chem 1997;272:31221-31224.

5. Ibraghimov-Beskrovnaya O, Ervasti JM, Leveille CJ, et al. Primary structure of dystrophin-associated glycoproteins linking dystrophin to the extracellular matrix. Nature 1992;355:696-697.

6. Ozawa E, Noguchi S, Mizuno Y, et al. From dystrophinopathy to sarcoglycanopathy: evolution of a concept of muscular dystrophy. Muscle Nerve 1998;21:421-438.

7. Peters MF, Adams ME, Froehner SC. Differential association of syntrophin pairs with the dystrophin complex. J Cell Biol 1997;138: 81-93.

8. Lidov HG, Byers TJ, Kunkel LM. The distribution of dystrophin in the murine central nervous system: an immunocytochemical study. Neuroscience 1993;54:167-187.

9. Kim TW, Wu K, Xu JL, et al. Detection of dystrophin in the postsynaptic density of rat brain and deficiency in a mouse model of Duchenne muscular dystrophy. Proc Natl Acad Sci USA 1992;89:11642-11644.

10. Haenggi T, Soontornmalai A, Schaub MC, et al. Immunolocalization of dystrobrevin in the astrocytic endfeet and endothelial cells in the rat cerebellum. Neuroscience 2004;129:403-413.

11. Kim TW, Wu K, Black IB. Deficiency of brain synaptic dystrophin in human Duchenne muscular dystrophy. Ann Neurol 1995;38:446-449.

12. Nico B, Paola Nicchia G, Frigeri A, et al. Altered blood-brain barrier development in dystrophic MDX mice. Neuroscience 2004;125: 921-935.

13. Frigeri A, Nicchia GP, Nico B, et al. Aquaporin-4 deficiency in skeletal muscle and brain of dystrophic mdx mice. FASEB J 2001;15:90-98.

14. Nico B, Frigeri A, Nicchia GP, et al. Severe alterations of endothelial and glial cells in the blood-brain barrier of dystrophic mdx mice. Glia 2003;42:235-251.

15. Nico B, Frigeri A, Nicchia GP, et al. Role of aquaporin-4 water channel in the development and integrity of the blood-brain barrier. J Cell Sci 2001;114:1297-1307.

16. Nico B, Mangieri D, De Luca A, et al. Nerve growth factor and its receptors TrkA and p75 are upregulated in the brain of $\mathrm{mdx}$ dystrophic mouse. Neuroscience 2009;161:1057-1066.

17. Saadoun S, Papadopoulos MC, Davies DC, et al. Aquaporin-4 expression is increased in oedematous human brain tumours. J Neurol Neurosurg Psychiatry 2002;72:262-265.

18. Blake DJ, Hawkes $R$, Benson MA, et al. Different dystrophin-like complexes are expressed in neurons and glia. J Cell Biol 1999;147: 645-658. 
19. Jancsik V, Hajos F. The demonstration of immunoreactive dystrophin and its developmental expression in perivascular astrocytes. Brain Res 1999;831:200-205.

20. Lederfein D, Levy Z, Augier N, et al. 71-kilodalton protein is a major product of the Duchenne muscular dystrophy gene in brain and other nonmuscle tissues. Proc Natl Acad Sci USA 1992;89:5346-5350.

21. Lidov HG, Byers TJ, Watkins SC, et al. Localization of dystrophin to postsynaptic regions of central nervous system cortical neurons. Nature 1990;348:725-728.

22. Guadagno $\mathrm{E}$, Moukhles H. Laminin-induced aggregation of the inwardly rectifying potassium channel, Kir4.1, and the water permeable channel, AQP4, via a dystroglycan-containing complex in astrocytes. Glia 2004;47:138-149.

23. Connors NC, Adams ME, Froehner SC, et al. The potassium channel Kir4.1 associates with the dystrophin-glycoprotein complex via alphasyntrophin in glia. J Biol Chem 2004;279:28387-28392.

24. Leonoudakis D, Conti LR, Anderson S, et al. Protein trafficking and anchoring complexes revealed by proteomic analysis of inward rectifier potassium channel Kir2.x; -associated proteins. J Biol Chem 2004;279:22331-22346.

25. Neely JD, Amiry-Moghaddam M, Ottersen OP, et al. Syntrophindependent expression and localization of Aquaporin-4 water channel protein. Proc Natl Acad Sci USA 2001;98:14108-14113.

26. McCoy ES, Haas BR, Sontheimer H. Water permeability through aquaporin-4 is regulated by protein kinase $\mathrm{C}$ and becomes ratelimiting for glioma invasion. Neurosci 2010;168:971-981.

27. Sotgia F, Bonuccelli G, Bedford M, et al. Localization of phospho-betadystroglycan pY892; to an intracellular vesicular compartment in cultured cells and skeletal muscle fibers in vivo. Biochem 2003;42: 7110-7123.

28. Nico B, Tamma R, Annese T, et al. Glial dystrophin-associated proteins, laminin and agrin, are downregulated in the brain of mdx mouse. Lab Invest 2010;90:1645-1660.

29. McKay LI, DuBois DC, Sun YN, et al. Corticosteroid effects in skeletal muscle: gene induction/receptor autoregulation. Muscle Nerve 1997;20:1318-1320.

30. Bushby K, Finkel R, Birnkrant DJ, et al. DMD Care Considerations Working Group. Diagnosis and management of Duchenne muscular dystrophy, part 1: diagnosis, and pharmacological and psychosocial management. Lancet Neurol 2010;9:77-93.

31. Jobling Al, Augusteyn RC. What causes steroid cataracts? A review of steroid-induced posterior subcapsular cataracts. Clin Exp Optom 2002;85:61-75.

32. Hoffman EP, Dressman D. Molecular pathophysiology and targeted therapeutics for muscular dystrophy. Trends Pharmacol Sci 2001;22:465-470.

33. Jacobs SC, Bootsma AL, Willems PW, et al. Prednisone can protect against exercise-induced muscle damage. J Neurol 1996;243:410-416.

34. Takagi A, Watanabe T, Kojima S, et al. Effect of long-term administration of prednisolone on serum creatine kinase and muscle pathology of mdx mouse. Rinsho Shinkeigaku 1998;38:724-728.

35. Cozzoli A, Nico B, Sblendorio VT, et al. Enalapril treatment discloses an early role of angiotensin II in inflammation- and oxidative stress related muscle damage in dystrophic mdx mice. Pharmacol Res 2011; 64:482-492.

36. Cozzoli A, Rolland JF, Capogrosso RF, et al. Evaluation of potential synergistic action of a combined treatment with alpha-methylprednisolone and taurine on the mdx mouse model of Duchenne muscular dystrophy. Neuropathol Appl Neurobiol 2011;37:243-256.

37. Miura $P$, Andrews $M$, Holcik $M$, et al. IRES-mediated translation of utrophin $A$ is enhanced by glucocorticoid treatment in skeletal muscle cells. PLoS One 2008;3:e2309.

38. Förster C, Silwedel C, Golenhofen N, et al. Occludin as direct target for glucocorticoid-induced improvement of blood-brain barrier properties in a murine in vitro system. J Physiol 2005;565:475-486.

39. De Luca A, Pierno S, Liantonio A, et al. Enhanced dystrophic progression in mdx mice by exercise and beneficial effects of taurine and insulin-like growth factor-1. J Pharmacol Exp Ther 2003;304:453-463.

40. De Luca A. Use of grip strength meter to assess the limb strength of $\mathrm{mdx}$ mice 2008. http://www.treat-nmd.eu/resources/researchresources/dmd-sops/.

41. Burdi R, Rolland JF, Fraysse B, et al. Multiple pathological events in exercised dystrophic mdx mice are targeted by pentoxifylline: outcome of a large array of in vivo and ex vivo tests. J Appl Physio 2009;106:1311-1324.

42. Pfaffl MW. A new mathematical model for relative quantification in real-time RT-PCR. Nucleic Acids Res 2001;29:e45.

43. Kissel JT, Burrow KL, Rammohan KW, et al. Mononuclear cell analysis of muscle biopsies in prednisone-treated and untreated Duchenne muscular dystrophy. Neurology 1991;41:667-672.

44. Manzur AY, Kuntzer T, Pike M, et al. Glucocorticoid corticosteroids for Duchenne muscular dystrophy. Cochrane Database Syst Rev 2008;23: CD003725.

45. Anderson JE, Appelbaum FR, Schoch G, et al. Allogeneic marrow transplantation for myelodysplastic syndrome with advanced disease morphology: a phase II study of busulfan, cyclophosphamide, and total-body irradiation and analysis of prognostic factors. J Clin Oncol 1996;14:220-226.

46. St-Pierre SJ, Chakkalakal JV, Kolodziejczyk SM, et al. Glucocorticoid treatment alleviates dystrophic myofiber pathology by activation of the calcineurin/NF-AT pathway. FASEB J 2004;18:1937-1939.

47. Vandebrouck C, Imbert N, Duport G, et al. The effect of methyl prednisolone on intracellular calcium of normal and dystrophic human skeletal muscle cells. Neurosci Lett 1999;269:110-114.

48. Abbott NJ, Patabendige AA, Dolman DE, et al. Structure and function of the blood-brain barrier. Neurobiol Dis 2010;37:13-25.

49. Fanning $A S$, Little BP, Rahner $C$, et al. The unique- 5 and -6 motifs of ZO-1 regulate tight junction strand localization and scaffolding properties. Mol Biol Cell 2007;18:721-731.

50. Mitic LL, Van Itallie CM, Anderson JM. Molecular physiology and pathophysiology of tight junctions I. Tight junction structure and function: lessons from mutant animals and proteins. Am J Physio Gastrointest Liver Physiol 2000;279:G250-G254.

51. Tsukita S, Furuse M. Occludin and claudins in tight-junction strands: leading or supporting players? Trends Cell Biol 1999;9:268-273.

52. Antonetti DA, Barber AJ, Hollinger LA, et al. Vascular endothelial growth factor induces rapid phosphorylation of tight junction proteins occludin and zonula occludens-1. A potential mechanism for vascular permeability in diabetic retinopathy and tumors. J Biol Chem 1999;274:23463-23467.

53. Furuse $M$, Hirase $T$, Itoh $M$, et al. Occludin: a novel integral membrane protein localizing at tight junctions. J Cell Biol 1993;123:1777-1788.

54. Morgan L, Shah B, Rivers LE, et al. Desmond H, Smith T, Staddon JM Inflammation and dephosphorylation of the tight junction protein occludin in an experimental model of multiple sclerosis. Neuroscience 2007;147:664-673.

55. Rao RK, Basuroy S, Rao VU, et al. Tyrosine phosphorylation and dissociation of occludin-ZO-1 and E-cadherin-beta-catenin complexes from the cytoskeleton by oxidative stress. Biochem J 2002;368:471-481.

56. Fischer S, Wobben M, Marti HH, et al. Hypoxia-induced hyperpermeability in brain microvessel endothelial cells involves VEGFmediated changes in the expression of zonula occludens-1. Microvasc Res 2002;63:70-80.

57. Murakami T, Felinski EA, Antonetti DA. Occludin phosphorylation and ubiquitination regulate tight junction trafficking and vascular endothelial growth factor-induced permeability. J Biol Chem 2009;284: 21036-21046.

58. Nico B, Mangieri D, Crivellato $E$, et al. HIF activation and VEGF overexpression are coupled with ZO-1 up-phosphorylation in the brain of dystrophic mdx mouse. Brain Pathol 2007;17:399-406.

59. Förster $C$, Waschke J, Burek $M$, et al. Glucocorticoid effects on mouse microvascular endothelial barrier permeability are brain specific. J Physiol 2006;573:413-425.

60. Kröll S, El-Gindi J, Thanabalasundaram G, et al. Control of the bloodbrain barrier by glucocorticoids and the cells of the neurovascular unit. Ann N Y Acad Sci 2009;1165:228-239.

61. Tenenbaum T, Matalon D, Adam R, et al. Dexamethasone prevents alteration of tight junction-associated proteins and barrier function in porcine choroid plexus epithelial cells after infection with Streptococcus suis in vitro. Brain Res 2008;1229:1-17.

62. Bojarski C, Weiske J, Schöneberg T, et al. The specific fates of tight junction proteins in apoptotic epithelial cells. J Cell Sci 2004;117: 2097-2107.

63. Kimura K, Teranishi S, Kawamoto K, et al. Protective effect of dexamethasone against hypoxia-induced disruption of barrier function in human corneal epithelial cells. Exp Eye Res 2011;92:388-393. 
64. Harkness KA, Adamson P, Sussman JD, et al. Dexamethasone regulation of matrix metalloproteinase expression in CNS vascular endothelium. Brain 2000;123:698-709.

65. Wolfensberger TJ, Gregor ZJ. Macular edema-rationale for therapy. Dev Ophthalmol 2010;47:49-58.

66. Abbott NJ, Rönnbäck L, Hansson E. Astrocyte-endothelial interactions at the blood-brain barrier. Nat Rev Neurosci 2006;7:41-53.

67. Katychev A, Wang X, Duffy A, et al. Glucocorticoid-induced apoptosis in CNS microvascular pericytes. Dev Neurosci 2003;25:436-446.

68. Nico B, Ribatti D. Aquaporins in tumor growth and angiogenesis. Cancer Lett 2010;294:135-138.

69. Warth $A$, Mittelbronn $M$, Wolburg $H$. Redistribution of the water channel protein aquaporin-4 and the $\mathrm{K}+$ channel protein Kir4.1 differs in low- and high-grade human brain tumors. Acta Neuropathol 2005; 109:418-426.

70. Zador Z, Bloch O, Yao X, et al. Aquaporins: role in cerebral edema and brain water balance. Prog Brain Res 2007;161:185-194.

71. Ding T, Gu F, Fu L, et al. Aquaporin-4 in glioma invasion and an analysis of molecular mechanisms. J Clin Neurosci 2010;17:1359-1361.

72. Gunnarson E, Axehult G, Baturina $G$, et al. Lead induces increased water permeability in astrocytes expressing aquaporin 4. Neuroscience 2005;136:105-114.

73. Kadohira I, Abe Y, Nuriya M, et al. Phosphorylation in the C-terminal domain of Aquaporin-4 is required for Golgi transition in primary cultured astrocytes. Biochem Biophys Res Commun 2008;377:463-468.

74. Nicchia GP, Rossi A, Mola MG, et al. Actin cytoskeleton remodeling governs aquaporin-4 localization in astrocytes. Glia 2008;56:1755-1766.

75. Noël G, Belda M, Guadagno E, et al. Dystroglycan and Kir4.1 coclustering in retinal Müller glia is regulated by laminin-1 and requires the PDZ-ligand domain of Kir4.1. J Neurochem 2005;94:691-702.

76. Fort PE, Sene A, Pannicke $T$, et al. Kir4.1 and AQP4 associate with Dp71- and utrophin-DAPs complexes in specific and defined microdomains of Müller retinal glial cell membrane. Glia 2008;56:597-610.

77. Culligan K, Glover L, Dowling $\mathrm{P}$, et al. Brain dystrophin-glycoprotein complex: persistent expression of beta-dystroglycan, impaired oligomerization of Dp71 and up-regulation of utrophins in animal models of muscular dystrophy 2001). BMC Cell Biol, 2:2.

78. Pichavant C, Aartsma-Rus A, Clemens PR, et al. Current status of pharmaceutical and genetic therapeutic approaches to treat DMD. Mol Ther 2011;19:830-840.

79. Uchino M, Hara A, Mizuno $\mathrm{Y}$, et al. Distribution of dystrophin and dystrophin-associated protein 43DAG beta-dystroglycan; in the central nervous system of normal controls and patients with Duchenne muscular dystrophy. Intern Med 1996;35:189-194.

80. Rurak J, Noel G, Lui L, et al. Distribution of potassium ion and wate permeable channels at perivascular glia in brain and retina of the Large myd; mouse. J Neurochem 2007;103:1940-1953.

81. Bozzi M, Morlacchi S, Bigotti MG, et al. Functional diversity of dystroglycan. Matrix Biol. 2009;28:179-187.

82. Mo KF, Fang $\mathrm{T}$, Stalnaker $\mathrm{SH}$, et al. Synthetic, structural, and biosynthetic studies of an unusual phospho-glycopeptide derived from $\alpha$-dystroglycan. J Am Chem Soc. 2011;133:14418-14430.

83. Yolande Rouiller, Arnaud Périlleux, Milène Marsaut, et al Effect of hydrocortisone on the production and glycosylation of an Fc-fusion protein in $\mathrm{CHO}$ cell cultures. Biotechnol Prog 2012;28:803-881.

84. Miura P, Chakkalakal JV, Boudreault $L$, et al. Pharmacological activation of PPARbeta/delta stimulates utrophin A expression in skeletal muscle fibers and restores sarcolemmal integrity in mature mdx mice. Hum Mol Genet 2009;18:4640-4649.

85. Gazzerro E, Assereto S, Bonetto A, et al. Therapeutic potential of proteasome inhibition in Duchenne and Becker muscular dystrophies. Am J Pathol 2010;176:1863-1877. 